ISSN: 2539-3804@®@

\title{
El español de Colombia. Nueva propuesta de división dialectal ${ }^{1}$
}

Néstor Fabián Ruiz Vásquez

Instituto Caro y Cuervo

Bogotá, Colombia

\section{Resumen}

El presente estudio ofrece una nueva división dialectal del español de Colombia, que ajusta las propuestas previas mediante la incorporación de datos lingüísticos y dialectológicos recientes, la elaboración de un nuevo modelo espacial de la estructuración dialectal basado en el concepto de escala, y la consideración de todo el territorio colombiano continental para la propuesta. El estudio identifica y caracteriza cinco nuevas variedades diatópicas previamente no consideradas en la discusión sobre el español colombiano, integra de modo coherente el español de Colombia en el marco del español americano, y señala algunas de las necesidades de la investigación dialectológica actual en el país.

Palabras clave: dialectología; español de Colombia; español de América; dialectos; isoglosas.

\begin{abstract}
The Dialects of Colombian Spanish: A New Classification

This paper proposes a new classification for the dialects of Colombian Spanish based on recent dialectological and linguistic data, a new model of the spatial variation of language grounded on the concept of scale, and consideration of all the continental Colombian territory. The study identifies five new geographic varieties of Spanish, integrates seamlessly and coherently the varieties of Colombian Spanish with those of the Americas,
\end{abstract}

\footnotetext{
${ }^{1}$ El presente estudio es producto de las sesiones 2014 (I y II) y 2106 (I y II) del Seminario de Cambio y Variación Lingüística de la Facultad Seminario Andrés Bello. Debo agradecer aquí el entusiasmo y el rigor puesto en la realización de sus trabajos a los (entonces) estudiantes Mónica Ramírez, Ana Constanza Rodríguez, Youlín Ávila, Fabio Silva, Carlos Rodríguez, Fredy Mendieta y Johnatan Bonilla. Sus hallazgos hacen parte de las consideraciones ofrecidas en estas páginas. Deseo igualmente agradecer a mis colegas Juliana Molina, Edwin Algarra, Julio Bernal, Camilo Díaz y Alejandro Correa por la lectura de los borradores, las discusiones, y sus pertinentes aportes a esta propuesta, y a los lectores anónimos por sus observaciones y notas sobre el manuscrito
} 
and identifies some new research avenues in the field of Spanish Dialectology in Colombia.

Palabras clave: dialectology; Colombian Spanish; Spanish of the Americas; dialects; isoglosses.

\section{Résumé}

\section{Les dialectes de l'espagnol colombien : une nouvelle classification}

Cet article propose une nouvelle classification des dialectes colombiens de l'espagnol qui redéfinie les propositions préalables à travers l'intégrations de données dialectologiques et linguistiques récents, l'élaboration d'un nouveau modèle de variation spatiale de la langue, fondé sur le concept d'échelle, et la prise en compte de l'ensemble du territoire colombien continental. L'étude identifie cinq nouvelles variétés géographiques de l'espagnol, qui n'avaient pas été considérées dans la discussion, et intègre également de manière cohérente les variétés de l'espagnol de la Colombie dans le cadre de l'espagnol de Amériques. De même, ce travail met en évidence le besoin de poursuivre la recherche dans le domaine de la dialectologie de l'espagnol en Colombie.

Mots-clés : dialectologie ; espagnol colombien ; espagnol des Amériques ; les dialectes ; isoglosses. 


\section{CÓMO CITAR ESTE ARTÍCULO}

Ruiz, N. (2020). El español de Colombia. Nueva propuesta de división dialectal. Lenguaje, 48(2), 160-195. doi: 10.25100/lenguaje.v48i2.8719 


\section{INTRODUCCIÓN}

La variación geográfica de las lenguas y la concreción de este fenómeno en variedades diatópicas es un hecho del que todo hablante tiene experiencia directa, por lo que no requiere demostración en lingüística. Diferente es el problema de la delimitación de las áreas dialectales, que ha ocupado a los investigadores desde el siglo XIX y visto diferentes respuestas, desde las isoglosas impresionistas de los inicios de la dialectología alemana hasta las modernas técnicas de análisis estadístico y cuantitativo de corpus. La estimación de las fronteras entre las variedades geográficas de una lengua continúa siendo de interés en la lingüística, en tanto el objeto que es delimitado cambia y se adapta a la trayectoria histórica de las comunidades, o en cuanto surgen nuevos métodos de investigación que permiten abordar viejos problemas lingüísticos desde ángulos novedosos. Ejemplos recientes de propuestas de división dialectal para el marco americano o general del español, como los estudios de Quesada (2014) o Sobrino (2018), realizados desde la perspectiva de la dialectología perceptual, muestran que el problema de las divisiones dialectales sigue vigente y, más allá, incorpora hoy nuevos elementos de juicio. En ese marco el presente estudio revisa la división dialectal del español de Colombia a la luz de datos recientes, ofrece una nueva articulación teórica de las variedades diatópicas colombianas, propone una nueva estructura (e isoglosas) para diferenciarlas, así como una mejor perspectiva de integración de Colombia en el conjunto americano. El trabajo se divide en tres secciones, en primer lugar se presentan las propuestas previas de división dialectal del español de Colombia, a continuación se exponen los nuevos datos disponibles y las consideraciones teóricas que fundamentan esta aproximación, para finalmente, en la tercera sección, desarrollar la propuesta.

\section{Propuestas de división dialectal del español de Colombia}

Aunque la pregunta por los dialectos del español de Colombia comienza en el siglo XIX con la búsqueda del ethos de la naciente república, será hasta mediados del siglo XX, con la recolección y publicación de los materiales del Atlas Lingüístico-Etnográfico de Colombia (ALEC) (Instituto Caro y Cuervo, 1981), que se alcance un conocimiento sistemático de las variedades diatópicas del territorio y una discusión sobre su extensión y límites según teorías dialectológicas. Así, iniciadas las encuestas para el ALEC en 1958, la primera propuesta de división dialectal será la de Flórez (1961), a la que seguirá la de Montes (1982) y posteriormente la del Departamento de Dialectología del Instituto Caro y Cuervo [ICC] (Mora, Lozano, Ramírez, Espejo y Duarte, 2004).

Si bien realizadas a partir de los mismos materiales, las tres propuestas resultan diferentes: la de Flórez es impresionista y preliminar (se publicó en una "nota informativa" antes de terminar las encuestas para el Atlas y a partir de los datos de las primeras 53 -de 262- localidades estudiadas); la de Montes es estructural-funcional, con 
fijación de áreas e isoglosas mediante la identificación de rasgos que van del nivel fonético al léxico; la de Mora et al. es estructural-funcional, pero fija sus áreas mediante el estudio de rasgos léxicos únicamente. Como elemento común, estas propuestas modelan la variación del español colombiano en sistemas jerárquicos, que van de la mayor a la menor extensión geográfica, y en los que las unidades dialectales del mismo nivel se oponen entre sí, mientras las unidades de niveles diferentes se subordinan según el grado de generalidad de sus rasgos distintivos. Ninguno de estos trabajos incluye a la Orinoquía y la Amazonía, regiones que dan cuenta de casi el $50 \%$ del territorio nacional; este aspecto se debe al diseño de la malla de poblaciones para el ALEC, que no estudió estas zonas o sus localidades por razones de acceso, antigüedad, densidad y composición poblacional.

Luis Flórez, formado a mediados del siglo XX por Navarro Tomás en Estados Unidos, elaboró su teoría dialectológica a partir de los postulados más tradicionales de la disciplina, según los cuales el dialecto es una lengua regional, o una modalidad de lengua usada en un cierto territorio y limitada por una serie de isoglosas, enfoque que orienta la investigación hacia la recolección de la mayor cantidad de datos para caracterizar cada modalidad regional y la descripción de sus límites ( $c f$. Alvar, 1996). La muestra que Flórez (1961) usó para su propuesta incluye localidades de las regiones del Caribe, Antioquia, el altiplano cundiboyacense, los Santanderes y Nariño. Su aproximación (que considera situados al mismo nivel de determinación rasgos de pronunciación, morfosintácticos y léxicos) delimita siete áreas dialectales (Figura 1): una superzona dialectal Costeña que cubre las costas colombianas sobre ambos océanos; en el interior, al occidente, distingue una zona Antioqueña, y otra Nariñense-Caucana que cubre la porción andina de Valle del Cauca, Cauca y Nariño; al oriente, establece una zona Santandereana, una Cundiboyacense y otra Tolimense-Huilense, y más al oriente, una zona Llanera (cf. Flórez, 1961). Flórez hace un listado de los datos más importantes hallados para cada área en todos los niveles de descripción de la lengua, mas no interpreta sus datos en un marco global o comparativo ni caracteriza las zonas creadas. Tampoco aporta datos para describir la zona llanera, ni para la Tolimense-Huilense. 
Fuente: elaboración propia con base en los datos de Flórez (1961)

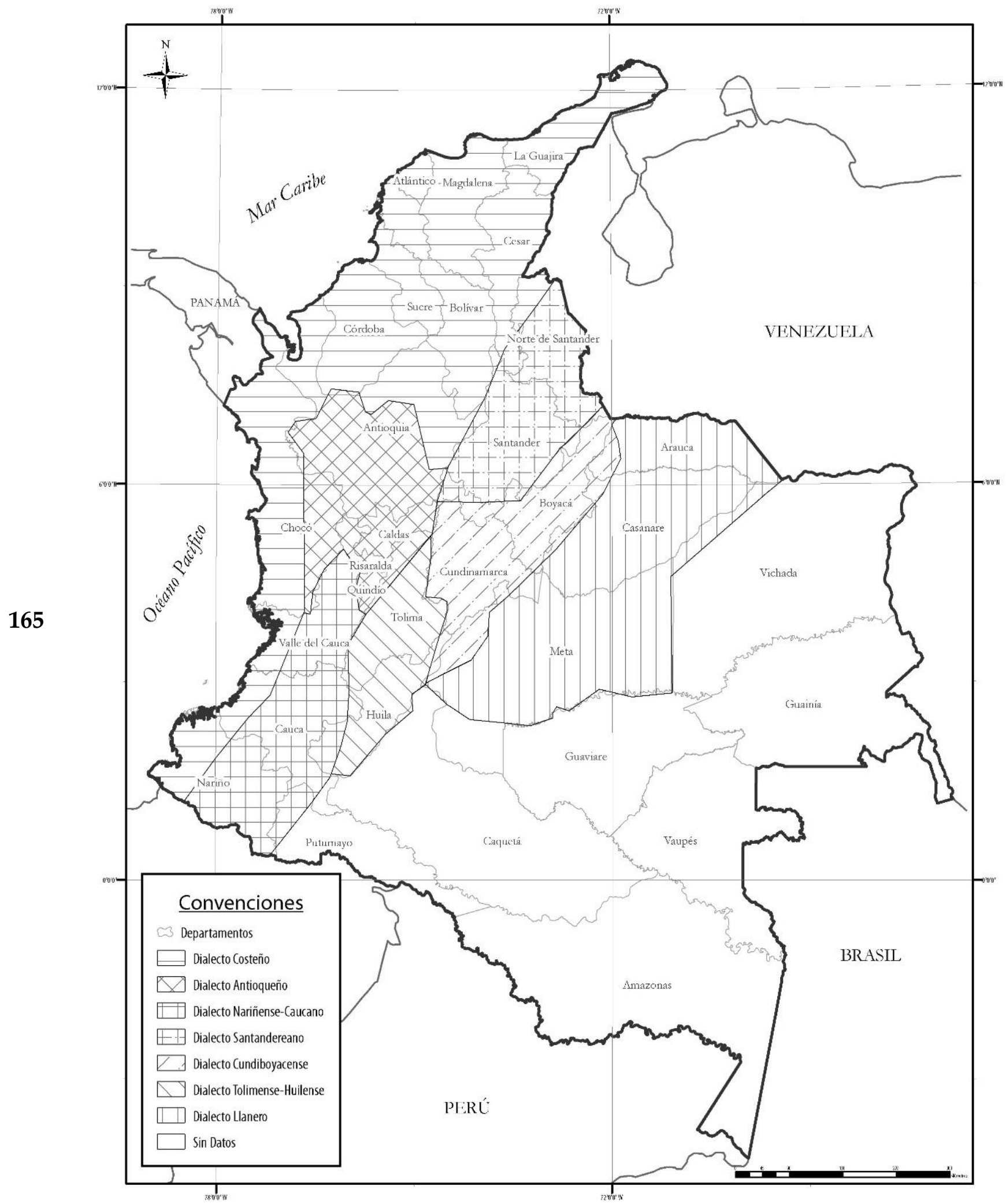

Figura 1. División dialectal del español de Colombia según Flórez (1961) 
Por su parte Montes, formado dentro del posestructuralismo coseriano, desarrolló su teoría dialectológica a partir de la triada Sistema-Norma-Habla y del concepto de Lengua Histórica: "una lengua es cualquier sistema comunicativo verbal histórico usado por determinada comunidad humana y caracterizado por su plenitud funcional y su autonomía normativa. Toda lengua histórica tiene también algún grado de polisistematicidad" (Montes, 1995a, p. 45). Dentro de su concepto es de gran importancia la polisistematicidad: "se puede decir que una lengua histórica no es nunca un solo sistema lingüístico, sino un diasistema, un conjunto más o menos complejo de "dialectos", "niveles" y "estilos de lengua"" (Coseriu, 1981, p. 306). En la concepción de Montes (como en la de Coseriu) la lengua histórica es una concreción: existe en el uso, en las normas de una comunidad dada, en las articulaciones históricas del hablar y en su desarrollo diacrónico, espacial, social y estilístico. Consecuentemente, su definición de dialecto como subsistema o variedad geográfica de una lengua incorpora aspectos históricos, funcionales y estructurales:

[dialecto es una] agrupación de las formas históricas del hablar caracterizado por un conjunto de normas, funcionalmente limitado y subordinado a una entidad mayor (la lengua), de la que hace parte y de la que toma la norma modelo, su ideal de lengua y las funciones que el dialecto no cumple normalmente. (Montes, 2000, p. 141).

En su concepción, la subordinación y la parcialidad son dos de las características que definen el dialecto y permiten considerarlo como variedad de una lengua ( $c f$. Montes, 1995a).

Dentro de ese marco, su propuesta de clasificación dialectal adopta como base la tesis de la división de la lengua española (considerada como lengua histórica) en dos grandes conjuntos: "parto, pues, de una primera gran división dialectal del español entre español centro-septentrional y español meridional, predominante en América en las islas y tierras bajas en general, y trataré de mostrar cómo se refleja tal bipartición en Colombia" (Montes, 1982, p. 30)². Para sustanciar su teoría, delimita las unidades en que se divide el español de Colombia en Superdialectos (definidos como conjuntos caracterizados por varias normas lingüísticas), Dialectos (definidos como agrupaciones caracterizadas por al menos una norma lingüística), Subdialectos (que define como subdivisiones de los dialectos basadas bien en aspectos léxicos o bien en rasgos fonéticos o morfosintácticos),

\footnotetext{
2 Esta bipartición general de las variedades de la lengua, sostenida en sus trabajos por investigadores como Lapesa (1980), Fernández-Sevilla (1980) o Catalán (1958), se enmarca en una discusión ya superada (la del andalucismo del español americano), pero fundamentada en hechos históricos como la preponderancia de Sevilla y Andalucía en los asuntos del Nuevo Mundo y la mayor densidad de migrantes meridionales a América durante el primer siglo de la ocupación española, seguida de una mayor densidad de migrantes septentrionales durante los siglos posteriores.
} 
y Hablas regionales (que define como subdivisiones de los subdialectos y que pueden ser alcanzadas con criterios de la misma índole). Montes (1982) también señala el peso que les da a las diferencias lingüísticas para elaborar la síntesis de esas unidades dialectales, otorgándoles a las diferencias fonéticas el mayor poder explicativo y alcance geográfico, seguidas por las diferencias en la morfología y la sintaxis, y finalmente las diferencias en el léxico ( $c f$. Montes, 1982). Aunque no lo declara explícitamente, relaciona las diferencias fonéticas con las unidades superdialectales, las morfosintácticas y léxicas con unidades dialectales, y las puramente léxicas con unidades subdialectales y de habla regional.

A partir de estos criterios distingue dos superdialectos: el Costeño, que se extiende a la región de los Llanos Orientales y tal como en la propuesta de Flórez (1961) abarca las tierras bajas del Caribe y el Pacífico; frente al Central o Andino, que ocupa las porciones andinas y de tierras bajas no costeras del territorio ${ }^{3}$. Al interior de esos dos superdialectos distingue, como subordinados, cuatro dialectos: dos que reparten el costeño en dialecto Pacífico y Caribe, respectivamente ${ }^{4}$, mientras otros dos dialectos organizan el superdialecto central en Centro-Occidental y Centro-Oriental ${ }^{5}$. A nivel subdialectal identificó nueve áreas basándose en rasgos léxicos, pero dado que su revisión e ilustración excedería los límites de la presente sección, no los desarrollamos. La propuesta se resume en la Tabla 1 y las figuras 2 y 3 ( $c f$. Montes, 1982).

Tabla 1. Propuesta de división dialectal del español de Colombia según Montes (1982) ${ }^{6}$

\begin{tabular}{|c|c|c|c|c|c|}
\hline \multirow{2}{*}{\multicolumn{2}{|c|}{$\begin{array}{c}\text { Costeño Pacífico } \\
\text { Septentrional (?) }\end{array}$}} & \multicolumn{3}{|c|}{ Costeño Caribe } & \multirow{2}{*}{$\begin{array}{c}\text { Superdialecto } \\
\text { Costeño }\end{array}$} \\
\hline & & Cartagenero & Samario & Guajiro & \\
\hline & al (?) & \multicolumn{3}{|c|}{ Costeño Caribe interior } & \\
\hline \multicolumn{2}{|c|}{ Centro Occidental } & \multicolumn{3}{|c|}{ Centro Oriental } & Superdialecto \\
\hline $\begin{array}{l}\text { Nariñense- } \\
\text { Caucano }\end{array}$ & Antioqueño & $\begin{array}{l}\text { Tolimense- } \\
\text { Huilense }\end{array}$ & Cundiboyacense & Santandereano & $\begin{array}{c}\text { Central o } \\
\text { Andino }\end{array}$ \\
\hline
\end{tabular}

\footnotetext{
${ }^{3}$ El criterio de distinción de estas dos macroáreas dialectales está dado por la articulación de la /-s/: aspirada o elidida en las costas, conservada en el interior; la articulación velarizada de /-n/ $\rightarrow$ [-n], general en las costas, ausente en el interior; y la mayor presencia en las costas de fenómenos de pronunciación relacionados con las variedades antillanas del español (neutralización de /r/-/l/, asimilación de secuencias consonánticas heterosilábicas, etc.).

${ }^{4}$ Siendo el criterio de distinción entre ambos la norma de tratamiento de confianza para la segunda persona: \{tú\} preferida en el Caribe, frente a \{vos\} preferida en el Pacífico (Montes (1982) también anotó, desde un principio, una "notoria coincidencia" léxica de la costa Pacífica con el área dialectal Nariñense-caucana como aspecto que la diferenciaba del Caribe).

${ }^{5} \mathrm{El}$ criterio de distinción entre ambos es fonético-fonológico, pues los datos del ALEC revelaron que el yeísmo (neutralización de la oposición $/ K /$ - /j/ en favor de /j/) se encontraba más avanzado en las hablas occidentales que en las orientales. Igualmente, es criterio de distinción para ambas áreas dialectales la frecuencia en el uso de quechuismos: mayor en el occidente, menor en el oriente.

${ }^{6}$ Adaptación de la tabla original presentada por Montes (1982). Las (?) del original indican una división hipotética, para la que en el momento no existía evidencia suficiente.
} 
Fuente: elaboración propia con base en los datos de Montes (1982)

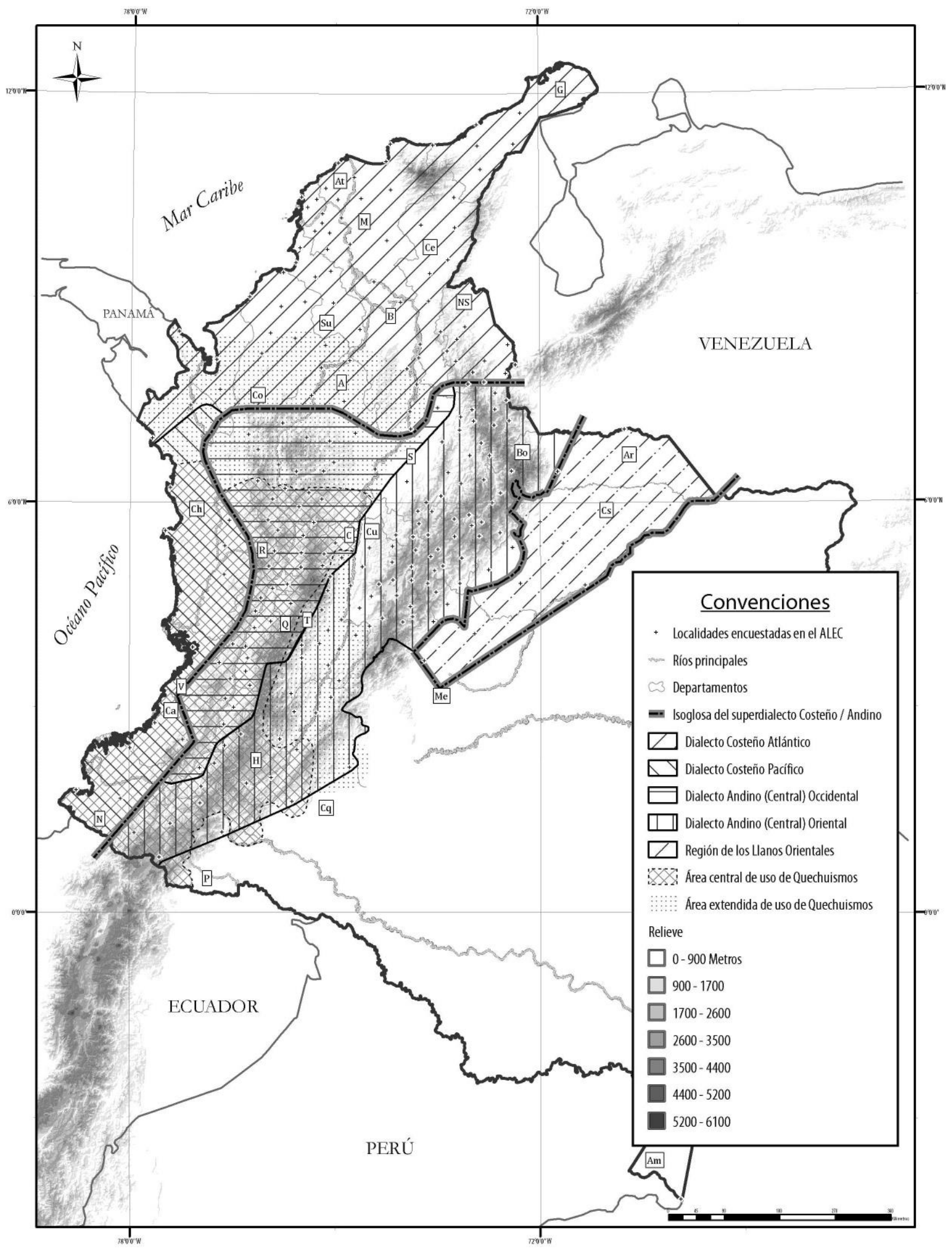

Figura 2. Dialectos del español de Colombia según Montes (1982) 


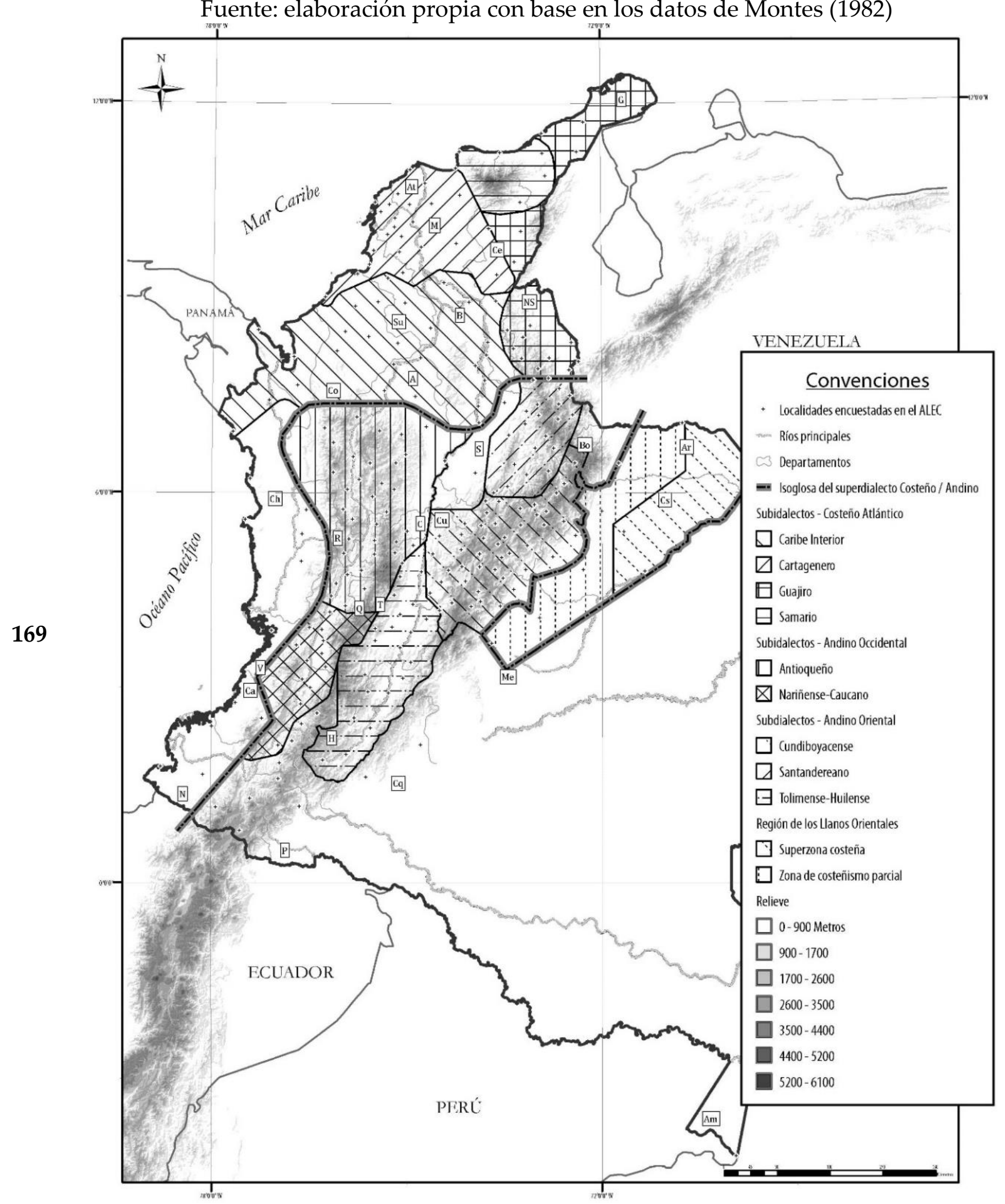

Figura 3. Subdialectos del español de Colombia según Montes (1982) 
Siervo Mora es el siguiente investigador que trabaja sobre el ALEC en la división dialectal del español de Colombia, primero con un artículo en el que, mediante la identificación de isoglosas léxicas, precisa la extensión de las áreas dialectales NariñenseCaucana y Antioqueña de la propuesta original de Montes, y las caracteriza, subdividiéndolas en tres subregiones: Antioqueño-Caldense al norte, Caucano-Valluno al centro, y Andino-Sureño al sur, logrando para el occidente andino del país una división más cercana a la estructura espacial y sociocultural de la región (cf. Mora, 1996). Él es igualmente el autor principal de la posterior Caracterización léxica de los dialectos del español de Colombia según el "ALEC" (Mora et al., 2004), último estudio de conjunto del Departamento de Dialectología del Instituto Caro y Cuervo, que a partir del mismo marco teórico posestructuralista de Montes identifica las áreas dialectales que quedaron por fuera de la propuesta de 1982, autoriza las isoglosas más importantes e incluye nuevos dialectos y subdialectos no precisados previamente. La propuesta de división dialectal resultante se resume en la Tabla 2 y las figuras 4 y 5 . El trabajo valida la bipartición costeño - andino que incluye en el área costeña a las costas del Pacífico; igualmente, además de incorporar la propuesta de Mora para el área occidental, confirma la distinción Norte Sur en los dialectos del Pacífico intuida por Montes en su propuesta original, y añade los datos para caracterizar (reclasificado dentro del superdialecto andino) el dialecto Llanero y los subdialectos Llanero norte y Llanero sur, incluso hasta el nivel de las hablas regionales. 
Tabla 2. Propuesta de división dialectal del español de Colombia según el Departamento de Dialectología del ICC (Mora et al., 2004) ${ }^{7}$

\begin{tabular}{|c|c|c|c|}
\hline Superdialectos & Dialectos & Subdialectos & Hablas Regionales \\
\hline \multirow{7}{*}{ Costeño } & \multirow{5}{*}{ Costeño Atlántico } & Cartagenero & Bolívar \\
\hline & & Samario & Cesar \\
\hline & & Guajiro & Guajira \\
\hline & & \multirow{2}{*}{ Atlántico Interior } & Córdoba \\
\hline & & & Sucre \\
\hline & \multirow{2}{*}{ Costeño Pacífico } & Pacífico Norte & \\
\hline & & Pacífico Sur & \\
\hline \multirow{11}{*}{ Andino } & \multirow{5}{*}{ Andino Occidental } & \multirow{2}{*}{ Antioqueño-Caldense } & Antioqueño \\
\hline & & & Caldense \\
\hline & & \multirow{2}{*}{ Caucano-Valluno } & Valluno \\
\hline & & & Caucano \\
\hline & & Andino-Sureño & Nariñense \\
\hline & \multirow{4}{*}{ Andino Oriental } & Santandereano & $\begin{array}{l}\text { Nortesantandereano } \\
\text { Santandereano }\end{array}$ \\
\hline & & Cundiboyacense & $\begin{array}{l}\text { Cundinamarqués } \\
\text { Bovacense }\end{array}$ \\
\hline & & \multirow[t]{2}{*}{ Tolimense-Huilense } & Tolimense \\
\hline & & & Huilense \\
\hline & \multirow{2}{*}{ Llanero } & Llanero Norte & $\begin{array}{l}\text { Araucano } \\
\text { Casanareño }\end{array}$ \\
\hline & & Llanero Sur & \\
\hline
\end{tabular}

${ }^{7}$ Adaptación de la tabla original presentada por Mora et al., (2004, p. 17). 
Fuente: elaboración propia con base en los datos de Mora et al. (2004)

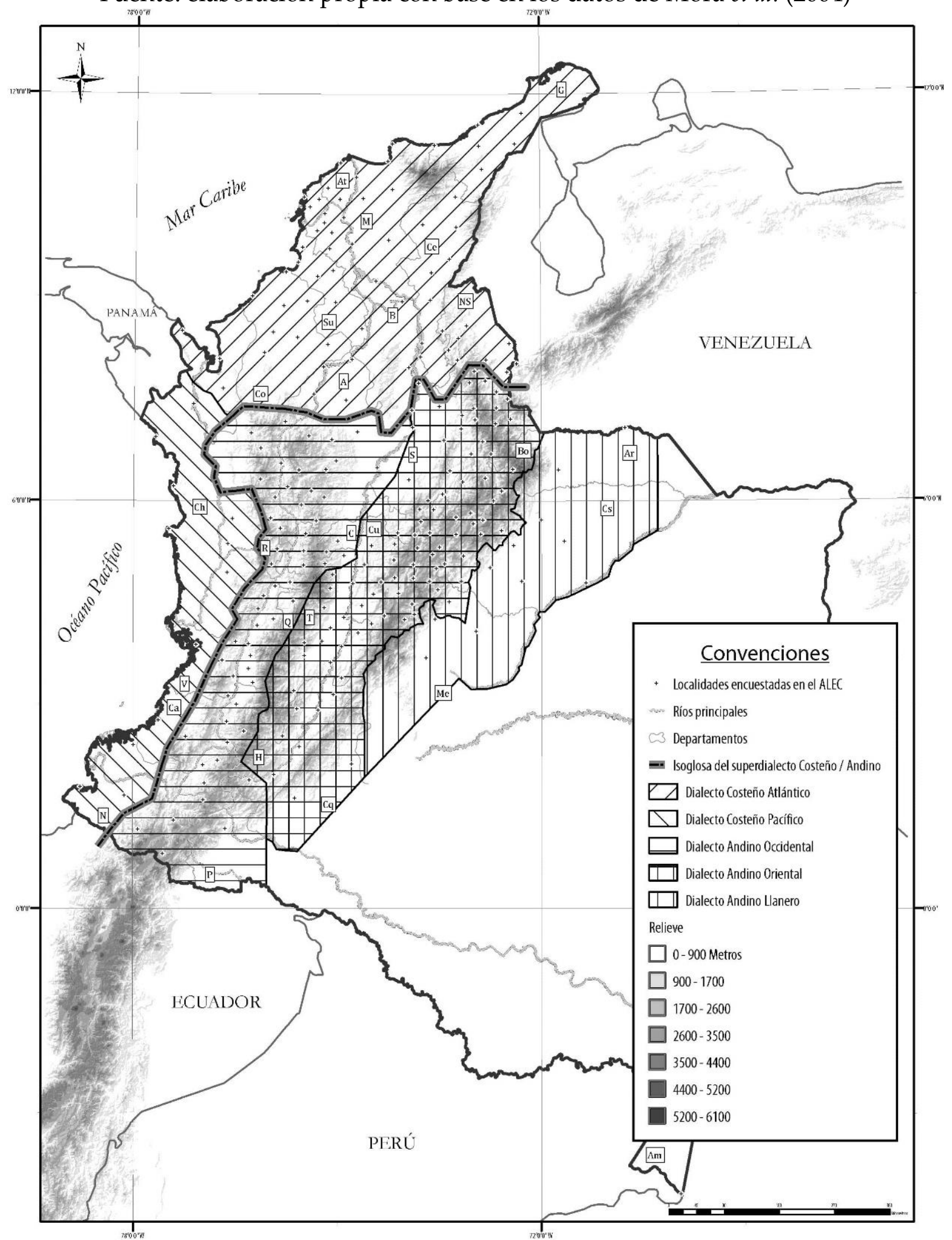

Figura 4. Dialectos del español de Colombia según el Departamento de Dialectología del ICC 
Fuente: elaboración propia con base en los datos de Mora et al. (2004)

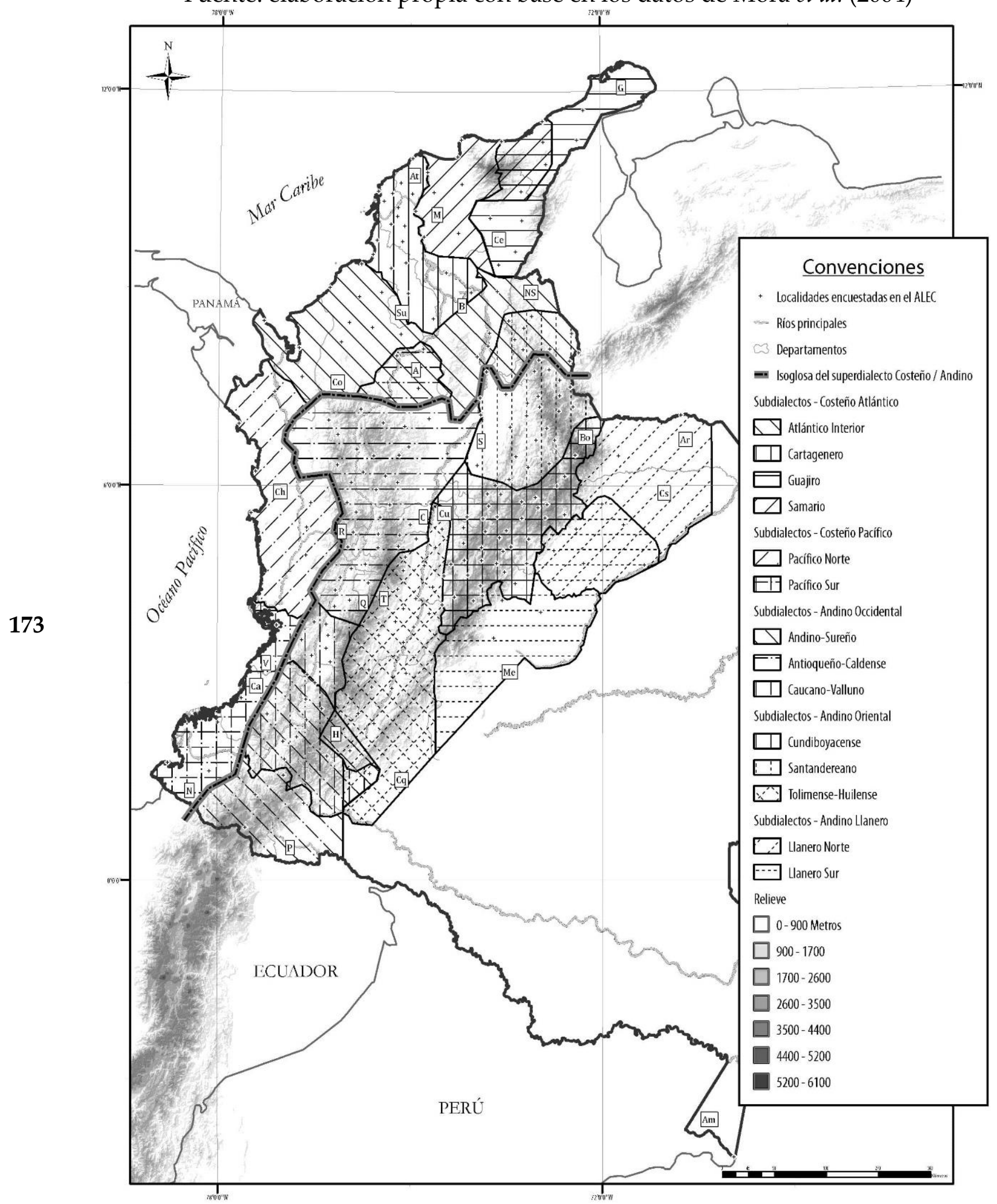

Figura 5. Subdialectos del español de Colombia según el Departamento de Dialectología del ICC 
Por fuera de los anteriores trabajos, los estudios que han abordado la variación diatópica del español de Colombia no han problematizado las propuestas de clasificación, por lo que tanto la estructura del entramado dialectal propuesta por Montes (1982), en una integración vertical que va de lo supra a lo subdialectal, como los límites más generales establecidos por él a partir de rasgos fonéticos y morfosintácticos, se consideran vigentes. Algunos trabajos recientes, como los de Brown y Brown (2012), Nieves (2002), o Rodríguez Cadena (2006), se han ocupado de aportar elementos para precisar áreas subdialectales o locales, dentro del marco de la propuesta de 1982 de Montes. Estudios de tipo dialectológico sobre el español de Colombia, como el de Bernal y Díaz (2017), el de Lancheros (2018), o el nuestro (Ruiz, 2014), adoptan la división de Mora et al. (2004) sin discutirla.

Dentro de las propuestas previas debe señalarse también la De Granda (1977), centrada en el área del Pacífico y elaborada a partir de isoglosas originadas en el léxico de la canoa y las embarcaciones de pesca. Su propuesta, sin relación con el antecedente de Flórez (1961) y publicada en un momento previo a la culminación del ALEC, segmenta el área del Pacífico en cuatro subzonas ${ }^{8}$, incorpora consideraciones fonéticas y morfosintácticas para caracterizar cada área dialectal, y estudia desde una perspectiva histórica su conformación. Se trata de un trabajo de notable valor para la dialectología del español de Colombia que no ha tenido una adecuada interlocución: Montes (1982) juzgó las isoglosas de De Granda como poco caracterizadoras, Mora et al. (2004) no lo referencian para su análisis léxico de la zona del Pacífico. Sin embargo, es en este trabajo que De Granda propone la existencia de un conjunto dialectal afropacífico que, comenzando en las costas panameñas, cruza las colombianas y sigue hacia las ecuatorianas (cf. De Granda, 1977).

\section{CONSIDERACIONES TEÓRICAS Y NUEVOS DATOS}

\section{Un nuevo modelo de la estructuración dialectal}

\section{Sobre el concepto Superdialecto en Montes}

La congruencia que exhibe el modelo de articulación diatópica de Colombia propuesto por Montes en 1982 ha llevado a que haya sido objeto de precisiones y validaciones, mas no críticas o reformulaciones. Si bien parece atrevido cuestionar una estructura que se revela coherente y respaldada por datos recogidos antes y después de la publicación del

\footnotetext{
${ }^{8}$ La partición inicial se establece entre una zona septentrional y una meridional, con su límite a la altura de Cértegui-Chocó. A su vez, la zona meridional se segmenta en dos subzonas con una isoglosa que corre de norte a sur, separando los territorios del litoral pacífico de los del piedemonte de la Cordillera Occidental; la zona meridional se segmenta de forma diferente, con una isoglosa que corre de oriente a occidente, a la altura de Riosucio-Antioquia, y divide el área en dos subzonas, una norte y otra sur.
} 
ALEC, el planteamiento de Montes tiene unas fallas de concepción que impiden desarrollarlo, como era su deseo, más allá de los límites del territorio colombiano, o dentro de otra discusión que no sea la de la bipartición dialectal del español en una variedad septentrional y otra atlántica y sus condicionamientos históricos. Resulta problemático en este sentido su concepto de superdialecto.

Debemos comenzar por señalar que la interpretación de Montes se sitúa en el último tercio del siglo $X X$, en un momento del desarrollo de la investigación sobre el español de América en el que la discusión tradicional alrededor de una "base" del español americano cedía ante las discusiones enfocadas en procesos de koineización, criollización y contacto lingüístico delimitadas por naciones o áreas de ocupación; Montes (1995b), si bien reconoció la utilidad de estas posiciones, mantuvo a lo largo de su obra y su docencia la postura de la bipartición del español en dos grandes variedades diatópicas, una meridional y otra septentrional -origen de su concepto de superdialecto, y en estrecha relación con el concepto de Español Atlántico de Catalán (cf. Catalán, 1958)-. También debe tenerse en cuenta que, debido a su concepción posestructuralista, el superdialecto en Montes (2012), al ser el nivel de mayor generalidad de la estructura dialectal, es de naturaleza binaria, y se define por la oposición en la articulación de un conjunto de rasgos: el superdialecto costeño se opone al andino por la diferencia en la articulación de /-s/, /$\mathrm{n} / \ldots$, la variedad septentrional se opone a la meridional por el uso de $/ \theta /$, el seseo, etc. En tal sentido, el concepto "superdialecto" construye dos conjuntos dialectales en vez de uno: si se define un superdialecto A, por oposición y contraste de rasgos lingüísticos, habrá uno B.

Aunque, como vimos a propósito de su propuesta, Montes (1982) se ocupó de definir el concepto "superdialecto" y de otorgarle al menos un rasgo distintivo para constituirlo como categoría, no avanzó en sus consideraciones teóricas o prácticas y, como resultado, lo usó de modo ambiguo. Por ejemplo, en su último trabajo publicado, en el que sintetiza su propuesta dialectológica y su modelo para la división del español en conjunto (Montes, 2012), "superdialecto" aparece usado explícitamente para determinar dos conjuntos de naturaleza y orden diferente: unidades de tipo nacional como el superdialecto Costeño colombiano, o unidades transnacionales como la variedad B-español Atlántico o meridional. Este uso indistinto de "superdialecto" para variedades con alcances geográficos, estructuras y desarrollos históricos no comparables se puede encontrar también en su estudio Para una teoría dialectal del Español (Montes, 1984), en el capítulo sobre Colombia en el Manual de Dialectología Hispánica de Manuel Alvar (Montes, 1996), o en su artículo La bipartición dialectal del español (Montes, 1995b), entre otros ejemplos.

También, Montes propuso y sostuvo desde sus primeros trabajos una continuidad histórica, geográfica y lingüística entre el superdialecto Costeño colombiano (al menos en su parte Caribe) y la variedad B o español Atlántico, lo que constituye un hecho demostrado, pero al mismo tiempo siempre consideró a la variedad colombiana como una unidad superdialectal diferente de la variedad B y así la clasificó a lo largo de su obra, lo que no 
resulta consecuente según su propia definición del concepto y dentro de los límites de su modelo; en principio, porque el hecho de escoger el modelo del español Atlántico como su base le otorga ya dos superdialectos opuestos, caracterizados por rasgos y diferenciados, por lo que crear la misma unidad para el español de una región americana es contradictorio; de modo más detallado, si partimos, como Montes (1984), de dos superdialectos del español, A y B, y encontramos que el español de nuestra costa Caribe acusa los rasgos de la variedad B, lo consecuente es clasificar a la variedad colombiana como dialecto, o en todo caso como subordinada a un conjunto mayor que es la variedad $\mathrm{B}^{9}$. La clasificación de las hablas costeras colombianas como superdialecto (dentro de un superdialecto ya existente), altera en últimas las relaciones de subordinación del modelo y dificulta establecer los niveles de oposición e incluso el inventario de rasgos lingüísticos que las caracteriza.

Montes (1995b, 2012) escogió el modelo de la bipartición del español y el concepto de superdialecto con la intención de insertar a Colombia en el marco americano e histórico del español, sin embargo, elementos que subyacen en la articulación misma de esos constructos impiden llevar a cabo ese objetivo. El superdialecto, y la concepción subordinante que se deriva de él, se ajustan bien para interpretar la articulación diatópica del país, determinada por una oposición Andes-costas que se traslada con fluidez a un modelo binario basado en oposición de rasgos lingüísticos; sin embargo, esa misma binariedad del modelo cierra la estructura sobre sí misma y no facilita el diálogo con otras realidades dialectales americanas: la oposición Andino-Costeño de Montes no se verifica, o al menos no a través de los mismos rasgos y oposiciones, en Ecuador, Venezuela, Panamá o las Antillas. Preguntas como ¿el español del Caribe venezolano es un dialecto o un superdialecto?, y de ser un superdialecto, ¿se relaciona con el español costeño colombiano?, ¿conforman la misma o dos unidades dialectales? ilustran el modo en que la binariedad y la concepción de máximo nivel de generalidad del superdialecto dificultan la integración de Colombia en el marco americano. Del mismo modo, si bien el modelo de la bipartición del español permite integrar a las variedades colombianas en el marco general e histórico del español, también es cierto que limita su comprensión, dificulta la subordinación de las unidades menores, y sobre todo, introduce una serie de problemas, como la continuidad geográfica de los superdialectos y sus rasgos distintivos, que en la práctica no facilitan la tarea de la descripción de las variedades diatópicas y sus relaciones.

\footnotetext{
${ }^{9}$ Esta interpretación, sin embargo, genera problemas en varios niveles: si el español del Caribe colombiano es un dialecto de la variedad B, ¿las variedades del interior son clasificables como dialectos o superdialectos?, ¿las hablas del interior se oponen a las de nuestra costa Caribe, o a las de todo el dominio antillano?, consecuentemente, ¿las variedades del interior resultan dialectos del superdialecto A o septentrional?, y de ser así ¿se subordinan al español septentrional a pesar de la falta de continuidad geográfica o de rasgos lingüísticos (como el uso de $/ \theta /)$ ?
} 


\section{Un nuevo modelo de la estructuración dialectal}

Para elaborar esta propuesta reconocemos como punto de partida la utilidad del concepto superdialecto, y del modelo de estructuración diatópica propuesto por Montes (1982), que adoptamos, junto con sus fundamentos teóricos. Desde tal base proponemos que el concepto superdialecto necesita especificación en dos sentidos: en términos de su extensión geográfica, y de su configuración como unidad dialectal. Como se señaló, Montes lo usa indistintamente para especificar variedades de alcance nacional o transnacional, y argumentamos que el último es su valor apropiado: el estado de los estudios sobre el español de América, y las propuestas de división dialectal para las variedades americanas, muestran la existencia de superdialectos reales y estudiados como tal, incluso desde perspectivas diacrónicas, como el español antillano, el español andino, o el español rioplatense, todos ellos con la característica de abarcar más de una nación o al menos extender su influencia normativa sobre áreas geográficas muy extensas. La anterior observación constituye un hecho comprobado, al menos para las variedades mencionadas, y hace parte de discusiones vigentes, por lo que no nos detendremos en su demostración ${ }^{10}$. El superdialecto, entonces, describirá unidades diatópicas, en principio, de tipo transnacional.

Proponemos también un cambio en la configuración de las unidades dialectales del modelo, basándonos en consideraciones geográficas e incorporando conceptos del análisis espacial. Dado que es característica principal del superdialecto ser una unidad de carácter transnacional, o de cobertura de amplios territorios, tomamos el criterio de escala geográfica ${ }^{11}$ para constituirlo y entender sus categorías subordinadas, para lo cual pondremos en relación la variación espacial con un modelo estadístico básico.

Construimos el modelo creando una distribución normal mediante un intervalo de porcentajes que va de 0 a $100 \%$, donde $100 \%$ expresa la superficie total del territorio estudiado (para Colombia, 1.142.748 $\mathrm{km}^{2}$ ). A partir de ahí, ponderamos el peso y la dimensión de las unidades dialectales dividiendo el intervalo en cuartiles: 0 a $25 \%$, 25$50 \%$, etc., y considerando cada cuartil una escala dialectal; una salvedad que introducimos en la medición es que, en tanto estamos tratando de describir la variación diatópica, debemos reconocer la subordinación y la acumulación de rasgos entre niveles

\footnotetext{
10 Resultaría extenso dar cuenta de las referencias bibliográficas que sustentan la existencia de estos macroconjuntos dialectales. Referimos al lector, entre un número considerable de manuales, a Hualde, Olarrea, Escobar y Travis (2001), Aleza y Enguita (2010), o Lipski (2005) quienes ofrecen una visión general de estas áreas y sus rasgos.

${ }^{11}$ Entendemos el concepto de este modo: "con [escala geográfica] nos referimos a la esfera o área de influencia de procesos que determinan, afectan o cambian las distribuciones y variaciones espaciales de determinado lugar" (Sánchez, 2012, p. 16). Usualmente se aplican categorías de escala como Transnacional, Nacional, Regional, Local, etc., a espacios geográficos o culturales que igualmente pueden ir de la mayor a la menor extensión. Mediante el concepto de escala queremos expresar en esta propuesta el alcance geográfico de la variación diatópica y entender su estructura.
} 
(un rasgo lingüístico que se encuentre a nivel superdialectal aparecerá siempre en un dialecto o subdialecto subordinado), dado lo anterior, y también ajustando el intervalo del modelo para que refleje mejor la dimensión espacial (pues siempre las unidades superiores de la estructuración dialectal se corresponden con áreas geográficas cada vez más extensas) dividimos cada cuartil a su vez en ocho para poder construir unidades desiguales en escala y proporción pero comparables entre sí dada la subordinación por rasgos lingüísticos.

Con los anteriores elementos generamos un modelo de escala dialectal, en el que las hablas locales se definen por ocupar, en términos de escala, entre 1 y 3,12\% del territorio estudiado, los subdialectos entre 3,12 y $12,5 \%$, los dialectos entre 12,5 y $50 \%$ y los superdialectos, o bien son unidades de carácter transnacional, u ocupan entre el 50 y el $100 \%$ del espacio de un territorio estudiado. Esta forma de concebir la estructuración dialectal presenta, al menos teóricamente, algunas ventajas sobre el modelo de Montes (1982), siendo la más importante que libera el concepto de superdialecto (o a sus subordinados) de la necesidad de que exista una oposición estricta entre rasgos para constituir las unidades, pues el criterio de distinción deja de ser contrastivo (oposición de rasgos lingüísticos entre áreas) y pasa a ser geográfico (área de extensión de un rasgo determinado). Dependiendo de la extensión de un territorio, pueden existir uno, dos, o más superdialectos, cada uno caracterizado por un conjunto de rasgos lingüísticos, pero clasificados como tal en función de su extensión geográfica propiamente dicha. Igualmente, si en un territorio nacional dado se encuentra que ninguna variedad domina 178 más del $50 \%$ del espacio, se puede concluir que la variación diatópica no se estructura en superdialectos sino a través de relaciones situadas en el siguiente nivel, el de los dialectos. Esta manera de medir la estructuración dialectal no impide tampoco concebir un territorio en el que exista un único superdialecto que subordine la variación, y nos permite, finalmente, proponer un nivel más de la estructuración diatópica no identificado previamente, el del habla local, que relacionamos con variedades o rasgos de núcleos poblacionales específicos. La Tabla 3 sintetiza el modelo. 
Tabla 3. Modelo de escala dialectal

\begin{tabular}{ll}
\hline Nivel & Estructura normativa y espacial \\
\hline Superdialecto & $\begin{array}{l}\text { Variedad diatópica caracterizada por un conjunto de } \\
\text { normas lingǘsticas fonéticas (pero no exclusivamente), de } \\
\text { alcance usualmente transnacional, o nacional (mayor al } 50 \% \\
\text { del territorio de una nación) }\end{array}$ \\
\hline Dialecto & $\begin{array}{l}\text { Variedad diatópica caracterizada por al menos una norma } \\
\text { lingǘstica fonética, morfosintáctica o léxica, de alcance } \\
\text { usualmente regional (entre 12,5 y } 50 \% \text { del territorio de una } \\
\text { nación) }\end{array}$ \\
\hline Subdialecto & $\begin{array}{l}\text { Variedad diatópica caracterizada por al menos una norma } \\
\text { lingǘstica fonética, morfosintáctica o léxica, de alcance } \\
\text { usualmente local (entre 3,12 y 12,5\% del territorio de una } \\
\text { nación) }\end{array}$ \\
\hline Habla regional & $\begin{array}{l}\text { Variedad diatópica caracterizada por al menos una norma } \\
\text { lingüística fonética, morfosintáctica o léxica, de alcance } \\
\text { usualmente intralocal (entre 1 y 3,12 \% del territorio de una } \\
\text { nación) }\end{array}$ \\
\hline Habla local & $\begin{array}{l}\text { Variedad diatópica caracterizada por al menos una norma } \\
\text { lingüística fonética, morfosintáctica o léxica, de alcance } \\
\text { usualmente puntual (a nivel de un núcleo poblacional) }\end{array}$ \\
\hline
\end{tabular}

A partir de estas consideraciones se impide la ambigüedad en el uso de "superdialecto" y se otorgan unas medidas de cobertura geográfica de las variedades diatópicas que, aunque estimadas a partir de un modelo estadístico básico, dan una idea del alcance que estos constructos pueden tener para categorizarse.

\section{Nuevos datos y consideraciones dialectológicas}

\section{Sobre el Superdialecto Costeño y su extensión}

Ha resultado problemática en las clasificaciones dialectales previas la extensión del superdialecto costeño dentro del territorio colombiano, abarcando ambas costas sobre el Caribe y el Pacífico, un paradigma impuesto por Luis Flórez (1961) y continuado por Montes $(1982)^{12}$. Este problema se manifiesta en la investigación sobre la división dialectal del español de América: las dos propuestas más rigurosas, la de Rona (1964) y la de Zamora y Guitart (1982), muestran para el territorio colombiano una estructuración

\footnotetext{
${ }^{12}$ Aun cuando en su propuesta, advirtió que los rasgos fonéticos que vinculan ambas costas están menos desarrollados en el Pacífico que en el Caribe, y que los rasgos propiamente caribeños se extienden en el Pacífico hasta la altura de Coredó-Chocó, sin penetrar más al sur (cf. Montes, 1982).
} 
diferente de la propuesta por Montes (1982), aun siendo construidas a partir de criterios idénticos a los usados por él para delimitar los dialectos colombianos (articulación de /s/, voseo, articulación de la oposición /K/ - /j/). En el estudio de Rona (1964), Colombia se divide en tres secciones: una caribeña al norte, que comparte rasgos con el Caribe venezolano, panameño y toda el área antillana, una andina al centro, que cubre las costas del Pacífico al occidente y los Llanos al oriente, y además se extiende a través de los Andes hacia Venezuela, y una sección centro-oriental que alcanza todo el territorio de la Amazonía. En el estudio de Zamora y Guitart (1982) se presenta un patrón similar y se precisa: un área caribeña al norte, vinculada con las costas de Venezuela, Panamá y las Antillas; un área andina al centro, vinculada con Venezuela (y que incluye los territorios amazónicos y orinoquenses), y como diferencia con la propuesta de Rona (1964), un área Pacífico deslindada de los Andes y continuada por la costa pacífica del Ecuador. De hecho, en la propuesta de Quesada (2014), elaborada con criterios muy diferentes de los sistémico-estructurales, la costa norte de Colombia, opuesta al interior andino, aparece más vinculada con Venezuela y Panamá que con el Pacífico. Sin pretender argumentar que son estas las divisiones "correctas", o que representan fielmente la realidad del territorio estudiado, creemos que es significativa la discrepancia entre los modelos americanos y el colombiano en la adscripción del Pacífico a la misma zona que el Caribe, y constituye una evidencia para cuestionar la extensión del superdialecto costeño.

La aplicación reciente de conceptos y métodos de la dialectometría a los materiales del ALEC ha dado como resultado un conjunto de trabajos que aportan argumentos en ese sentido. El primero de estos estudios es el de Ávila, Mendieta, Rodríguez-Álvarez, Rodríguez-Díaz y Silva (2015), quienes trabajaron con una muestra aleatoria de 100 mapas lingüísticos del ALEC y aplicaron una metodología expuesta por García (1999) para obtener índices de proximidad y distancia entre localidades. Los resultados tienen validez y representatividad estadística, y se ajustan en la mayoría de los casos a las divisiones dialectales propuestas. En esa misma línea, e interesado en producir una propuesta de división diatópica del español de Colombia, está el trabajo de Bonilla (2019). Su estudio, que se basa en el Índice Relativo de Identidad (IRI) de Hans Goebl (1987), procede por agrupación de similitudes a partir de una matriz de diferencias lingüísticas, y tiene como muestra 200 mapas lingüísticos del ALEC escogidos aleatoriamente.

Los mapas de dos divisiones producidos en ambos trabajos (Ávila et al., 2015, mapa 1; Bonilla, 2019, figura 7) muestran que a ese nivel de la estructuración dialectal se genera una distinción entre Caribe y resto del territorio, que no incluye al Pacífico. De manera coherente con este resultado, el Pacífico, en todas las divisiones y análisis propuestos en estos trabajos -mapas de seis y doce divisiones (Ávila et al., 2015, mapas 2 y 3); mapas de tres y ocho divisiones (Bonilla, 2019, figuras 9 y 11)-, se vincula con el interior andino antes que con el Caribe, o se perfila como un área dialectal propia.

Realizado a partir de un corpus diferente, está el trabajo de Rodríguez-Díaz, Jiménez, Dueñas, Bonilla y Gelbukh (2018). El equipo investigador recolectó a través de 
la red social Twitter un corpus de 28 millones de trinos registrados en 237 localidades del territorio colombiano, y los procesó estadísticamente de acuerdo con diferentes medidas y pruebas. El trabajo logra encontrar niveles de significancia y confianza estadística en sus pruebas para sostener que se puede observar una agrupación de los datos ${ }^{13}$ en dos unidades léxicas principales: la costa Caribe y el resto del territorio ( $c f$. Rodríguez-Díaz et al., 2018, figura 5).

Todos estos hallazgos son consecuentes con los estudios sobre el desarrollo histórico del Pacífico, que muestran cómo la región se pobló, estructuró y manejó desde centros andinos del interior, y al vaivén de los ritmos de la explotación del oro y la implantación de mano de obra esclava, lo que dio como resultado un área diferenciada del Caribe a nivel lingüístico, de procesos de formación histórica y de densidad y composición poblacional (cf. Granda, 1977). Comprueban así mismo la observación inicial de Montes (1982), según la cual los rasgos meridionales están "muy lejos" de tener en el Pacífico la generalidad que en el Caribe, y conducen a desestimar la macroárea costeña propuesta por Flórez (1961) y validada por Montes (1982) y Mora et al. (2004), deslindando de ella la zona Pacífico, que queda mejor descrita como parte de las variedades del interior, vinculada histórica y económicamente con las hablas andinas, y posiblemente (recuperamos la hipótesis de De Granda) sea un superdialecto propio, con presencia en Panamá, Colombia y Ecuador.

Sobre el yeísmo en Colombia

Los estudios de Espejo (2013) y Ordúz (2013) demuestran que el yeísmo ha alcanzado, o está a punto de culminar, su generalización como rasgo de la pronunciación para todo el territorio colombiano. En ese sentido, su utilidad como criterio para establecer la distinción entre el dialecto Andino Occidental y el Andino Oriental disminuye y debemos abandonarlo como criterio fonético que separe ambas variedades. Mantenemos entonces como criterio distintivo entre estos dialectos la frecuencia en el uso de quechuismos: mayor en el occidente, menor en el oriente, y proponemos que el voseo se reconozca como rasgo pertinente, en tanto se ha comprobado su mayor extensión y uso en todas las hablas del occidente, de Antioquia a Nariño incluyendo la costa pacífica (cf. Díaz Collazos, 2015; Montes, 1967, 1982).

\section{Sobre la pronunciación del fonema /-s/ en Colombia}

El estudio de Ramírez (2015), realizado sobre datos del ALEC y examinando algunas de sus grabaciones, revela que en el Atlas la realización de /-s/ no muestra una distinción

\footnotetext{
${ }^{13}$ Los investigadores proponen el concepto de "dialectono", que conciben como el límite entre áreas dialectales adyacentes, caracterizado por el grado de interacción entre las variedades delimitadas (cf. Rodríguez-Díaz et al., 2018).
} 
nítida entre zonas que la aspiran o la eliden frente a otras que la conservan; antes bien, presenta un continuo de variación que va de las realizaciones aspiradas y elididas hasta alófonos sonorizados, en el que si bien las costas (sobre todo la Caribe) son escenario de procesos de lenición, el interior muestra procesos de fortición y uso de alófonos no contemplados en ninguna caracterización dialectal previa. El trabajo propone que tales alófonos sean considerados y que las variantes sonoras integren el espectro de variación diatópica de /-s/ en Colombia. En el mismo sentido se han pronunciado investigadores como Díaz Romero (2017).

\section{NUEVA PROPUESTA DE DIVISIÓN DIALECTAL DEL ESPAÑOL DE COLOMBIA}

\section{Nuevos superdialectos identificados}

Comenzando por el nivel superior de la estructura, los datos existentes en la literatura sobre el español de América permiten concluir que en Colombia tienen presencia dos superdialectos del español (concebido bajo los términos que lo hemos definido aquí: unidad dialectal de carácter transnacional, o con una escala mayor al $50 \%$ del territorio estudiado) que no están relacionados genéticamente y en esa medida no son adyacentes; ambos cumplen con el criterio de transnacionalidad.

El primero es el Español antillano, una unidad dialectal que se extiende por las Antillas mayores y se vincula con las costas caribeñas de Panamá, Colombia y Venezuela, principalmente. Definida como una variedad diatópica producto del contacto entre variedades del español, se caracteriza por una mayor frecuencia de fenómenos de la pronunciación como la realización aspirada o elidida de /-s/, la realización velarizada de $/$-n/ $\rightarrow[-n]$, la neutralización $/ 1 /=/ \mathrm{r} /$, la asimilación de secuencias consonánticas heterosilábicas, etc. (cf. Alba, 2016). El superdialecto Español antillano se concreta en Colombia en un dialecto Caribeño colombiano, correspondiente al área cultural y geográfica del Caribe, y se ve caracterizado por la mayor frecuencia de los fenómenos de pronunciación, morfosintaxis y léxico antillano. Extraemos de su zona el área del Pacífico según las consideraciones hechas en el apartado previo.

El otro superdialecto del español americano que hace presencia en territorio colombiano es el Español andino. Definida como una variedad diatópica producto del contacto lingüístico Quechua-Español, el español andino abarca un área que cubre el noroeste argentino, los Andes bolivianos, peruanos, ecuatorianos, y el sur andino de Colombia hasta la altura del Valle del Patía. La variedad se caracteriza por rasgos como la realización asibilada de vibrante múltiple $/ \mathrm{r} /$ y de la secuencia $/ \mathrm{t} r /$, desafricación de / $\mathrm{t} /$ $\rightarrow\left[\int\right]$, uso de construcciones verbales con gerundio (de valor de pasado perfecto o con función de atenuación del mandato) o el uso de quechuismos (cf. Arboleda, 2000, 2002, 2012). La identidad de la variedad y el origen de sus rasgos en procesos de contacto lingüístico se refuerza por el hecho de existir en el territorio del Putumayo y su área de 
influencia comunidades hablantes de quechua introducidas desde la Conquista, que han mantenido su lengua hasta nuestros días en coexistencia con el español, marcando así una continuidad de procesos lingüísticos e históricos con el área andina suramericana. Proponemos que el Español Andino se concreta en Colombia en un dialecto Andino colombiano, correspondiente al área cultural y geográfica andina entre la frontera con el Ecuador al sur y el Macizo colombiano al norte, punto en el que los Andes se dividen en su avance en tres cordilleras; este dialecto Andino colombiano se ve caracterizado por la mayor frecuencia de los fenómenos de pronunciación, léxico y morfosintaxis identificados para el conjunto del Español Andino.

Queda entonces por designar un área que, sin ser de tipo transnacional, cumple el criterio de abarcar más del $50 \%$ del territorio, y que por ello podemos ubicar al nivel superdialectal: el interior del país, que incluye las regiones naturales del Pacífico, los valles interandinos de los ríos Cauca y Magdalena, los altiplanos cordilleranos, la Amazonía y la Orinoquía, macroárea que, como se desarrolló previamente, se distingue claramente del Caribe y los Andes del sur. Proponemos llamarlo Español neogranadino, para resaltar su posición intermedia entre el español andino y el antillano, y para distinguirlo históricamente de ellos. Una característica de este superdialecto es que articula regiones geográficas muy diferentes y extensas, con desarrollos históricos también divergentes, por lo que las variedades diatópicas que cobija, si bien pueden exhibir rasgos comunes, deben reconocerse como originadas en procesos diacrónicos diferentes. Todas estas variedades pueden caracterizarse a nivel superdialectal por dos rasgos fonéticos, la tendencia a la conservación de /-s/ y a aspirar la /-s-/ intervocálica y preacentual (cf. Brown y Brown, 2012; Ramírez y Almira, 2016).

\section{Nuevos dialectos y subdialectos identificados}

La vigencia del Español Andino en territorio colombiano implica la entrada de ese constructo dialectal en la discusión sobre el español hablado en Colombia, y dentro de los límites de este estudio, supone delimitar sus dialectos y subdialectos subordinados. Proponemos entonces que el dialecto Andino colombiano, concreción del Español Andino en Colombia, se divida en dos subdialectos, uno propiamente situado en los Andes (Nariño y Macizo colombiano), que llamamos Andino colombiano de tierras altas, frente a otro que resulta de la emigración y colonización del Putumayo y el piedemonte andino desde Nariño y el Macizo colombiano, al que llamamos Andino colombiano de tierras bajas.

Proponemos igualmente reconocer, así sea a un nivel teórico, general y provisional, las variedades del español habladas en los territorios no estudiados por el ALEC: la Orinoquía y la Amazonía. Si bien carecemos de estudios que nos permitan integrar las variedades de esas regiones a la presente propuesta a nivel de rasgos lingüísticos característicos, damos por cierta su existencia, las queremos legitimar como parte del entramado dialectal del país, y hacemos un llamado con sentido de urgencia para elaborar 
estudios lingüísticos que sistematicen los aspectos de la variación diatópica en esas vastas regiones del territorio. En este mismo sentido se pronuncian también Bernal y Díaz (2017) y Lancheros (2018).

Los límites que planteamos para estas áreas son hipotéticos y corresponden a fronteras naturales, regiones culturales y escalas de articulación regional, siendo nuestra fuente principal el Atlas de Colombia -Instituto Geográfico Agustín Codazzi [IGAC], 2002 especialmente los mapas de Resguardos indígenas (p. 109), Centros subregionales urbanos (p. 123), Regiones naturales (p. 173) y Distribución de la población rural (p. 199)junto a estudios históricos como los de Palacios y Safford (2002).

Proponemos entonces prolongar el dialecto Llanero hacia el oriente hasta abarcar el departamento de Vichada; este tercer segmento del dialecto será el subdialecto Llanero Este, caracterizado por una mayor frecuencia de fenómenos que a primera vista parecen vincular a los Llanos con el español antillano como intuyó Montes en su propuesta de 1982, pero que consideramos de origen histórico y cultural diferente, y ubicamos (lanzamos la hipótesis) como resultado de las relaciones seculares entre los Llanos venezolanos y colombianos. El Llanero Este también estaría caracterizado por una mayor frecuencia de fenómenos de bilingüismo y contacto, dada la presencia de resguardos y población indígena en la zona (cabe también la posibilidad de que en el Vichada se dé continuidad al Llanero norte identificado en propuestas de división previas).

Proponemos igualmente reconocer, para la región geográfica de la Amazonía, un dialecto Amazónico, que dividimos en dos subdialectos, uno Norte y otro Sur. El dialecto 184 amazónico tendría como límite al norte el río Guaviare, que marca la frontera entre las regiones naturales de la Orinoquía y la Amazonía, y al sur el Río Putumayo y el Río Amazonas, que marcan la frontera política de Colombia con Ecuador y Perú a lo largo de la selva. Al occidente, el límite estaría marcado por Puerto Leguízamo, centro urbano más avanzado sobre el Río Putumayo, y subiría a partir de ahí hacia el norte siguiendo el piedemonte cordillerano hasta encontrarse con la cuenca alta del Río Guaviare y la Sierra de la Macarena. Al oriente, la frontera con Brasil daría el límite. Con iguales criterios dividimos el dialecto en dos porciones norte y sur separadas por el río Apaporis, distinción que corresponde a la división natural y geográfica entre Amazonía Meridional y Septentrional. El dialecto amazónico estaría caracterizado por contener sobre todo variedades derivadas del contacto lingüístico y situaciones de bilingüismo, dada la extensión de los resguardos de la zona y la presencia de numerosos grupos indígenas que incluso se ubican en ambos lados de las fronteras. Es esperable una continuidad con el occidente colombiano en el uso de quechuismos, no sólo debido a la ocupación del territorio amazónico desde el occidente, sino también a los contactos a lo largo de la frontera con Ecuador y Perú con centros urbanos y comunidades hablantes de español u otras lenguas. En ese mismo sentido, son esperables fenómenos de contacto con el portugués a lo largo de la frontera con Brasil. 


\section{Áreas de contacto y transición}

Desde la propuesta de Montes de 1982 se ha reconocido la existencia de áreas de transición entre las variedades diatópicas nacionales, especialmente entre las del Caribe y las del interior. Concebimos el área de transición como la zona alrededor de una isoglosa que muestra mayor variabilidad lingüística, y en la que se pueden encontrar alternativamente, o coexistiendo, rasgos de cada una de las variedades separadas por la isoglosa ( $c f$. Chambers y Trudgill, 1998). Dos áreas cumplen en esta propuesta con estas condiciones. La primera se sitúa en la confluencia del español antillano y el español neogranadino, allí donde las cordilleras dan paso a las llanuras del Caribe; en esta zona los rasgos del interior se extienden dentro del caribeño y los rasgos caribeños se atenúan; es un avance de las hablas del interior hacia la costa, que se especifica a nivel subdialectal como una penetración del Antioqueño-Caldense y del Santandereano en las hablas de las tierras bajas. La segunda área se sitúa en el límite entre el español andino y el español neogranadino; aquí, los rasgos del español andino penetran hacia los dialectos occidental y oriental pero van perdiendo fuerza a medida que avanzan en dirección norte; a nivel subdialectal se especifica como un avance del Andino colombiano de tierras altas hacia el valle geográfico del Río Cauca y del Andino colombiano de tierras bajas hacia la región del Alto Magdalena y el Caquetá, respectivamente. A partir de esta identificación surgen dos ciudades capitales como escenario de un intenso contacto interdialectal: Popayán-Cauca, y

185 Florencia-Caquetá, situadas ambas en el área de transición entre el español andino y el neogranadino. Igualmente, la porción norte de Norte de Santander y el norte de Antioquia surgen como áreas de contacto interdialectal en la transición del neogranadino hacia el antillano.

También, la identificación de estas áreas de transición nos permite señalar regiones de tránsito y comunicación, y diferenciarlas así de límites abruptos entre variedades, que en Colombia existen, y están dados por la geografía principalmente. Por ejemplo, el límite entre las variedades occidental y oriental del interior está marcado por la masividad de la cordillera central; igualmente, el Pacífico se segrega del occidente por los picos de la cordillera occidental. En contraste, la transición entre Andes y tierras bajas del Caribe (sobre todo a lo largo del Río Magdalena), el Macizo colombiano y el sur andino, se muestran como regiones de tránsito e intercambio, manifiesto en la mayor complejidad que muestran las isoglosas léxicas en el área de transición.

\section{CONCLUSIONES}

A partir del nuevo modelo teórico de estructuración dialectal que hemos propuesto, Colombia se puede integrar en el marco americano de un modo más claro, sobre todo a nivel de la descripción de los grandes conjuntos diatópicos que hemos reconocido, e incluyendo también las áreas de transición y las nuevas áreas dialectales; la aplicación del 
concepto de escala y de criterios de medición estructurados desde el análisis espacial (al menos como horizonte inicial) resultan muy útiles en ese sentido, dado que liberan a la descripción dialectológica de la necesidad de verificar oposiciones lingüísticas entre variedades, y permiten alcanzar interpretaciones más cercanas al análisis geográfico. Igualmente, esta propuesta actualiza la discusión sobre la división dialectal del español de Colombia, tanto por la incorporación de nuevos datos y elementos, como por la identificación de necesidades de la investigación dialectológica, como la caracterización de las hablas orinoquenses y amazónicas, o el estudio detallado de las hablas de los Llanos y el Pacífico. En ese sentido es necesaria también una actualización completa del ALEC, que aproveche las herramientas tecnológicas actuales, estructure la investigación desde una perspectiva de corpus lingüístico, y trate de cubrir las áreas no estudiadas en el proyecto original del Atlas.

En general, esta propuesta únicamente redistribuye tres rasgos sistemáticos (el voseo, la articulación de /-s/ y la de /-n/), y elimina uno (el yeísmo) de la articulación dialectal del español de Colombia. Se mantienen todos los demás rasgos propuestos por Montes (1982) y Mora et al. (2004) como criterios diferenciadores. Ofrecemos nuestra interpretación en el siguiente esquema (ver también la Tabla 4 y las figuras 6 , 7 y 8 al final del apartado).

La oposición a nivel superdialectal se expresa mediante isoglosas fonéticas. La isoglosa que separa el Español Antillano del Español Neogranadino ${ }^{14}$ expresa las diferencias en la realización de /-s/ (conservada o sonorizada en el neogranadino, aspirada o elidida 186 en el antillano), /-n/ (nasal [-n] en el neogranadino, velar [-n] en el antillano), /-s-/ (tendencia a la aspiración en el neogranadino, en contexto intervocálico y preacentual) y en la neutralización de ///-/r/ (débil o ausente en el neogranadino, presente en el antillano). Del mismo modo, la isoglosa que separa el Español Andino del Español Neogranadino ${ }^{15}$ expresa las diferencias en la realización de $/ \mathrm{r} /(/ \mathrm{r} /$ asibilada en el andino, vibrante múltiple en el neogranadino) y la secuencia $/ \mathrm{t} r /(/ \mathrm{tr} / \rightarrow[\mathrm{d} z]$ en el andino, $/ \mathrm{tr} / \rightarrow[\mathrm{tr}]$ en el neogranadino).

La oposición a nivel dialectal se expresa mediante diferencias morfosintácticas y léxicas. El dialecto Neogranadino Occidental se diferencia a nivel morfosintáctico del Neogranadino Oriental por la mayor frecuencia del voseo en el trato informal, y a nivel léxico por la mayor frecuencia de los quechuismos; a su vez, el Neogranadino Oriental se diferencia del Occidental a nivel morfosintáctico por la mayor frecuencia en el uso de los

\footnotetext{
${ }^{14}$ Esta isoglosa, leyéndola de occidente a oriente, corre perpendicular a las estribaciones de las cordilleras occidental, central y oriental, desde la frontera con Panamá hasta la frontera con Venezuela. La isoglosa atraviesa el Magdalena Medio en su punto más ancho, justo en el centro del área de transición entre ambos superdialectos.

${ }^{15}$ Esta isoglosa se lee mejor como un arco, con su clave en el Valle del Patía, su contrafuerte izquierdo en el piedemonte andino occidental, y su contrafuerte derecho desplazado del piedemonte oriental, cubriendo una amplia porción de tierras bajas del Amazonas.
} 
pronombres \{tú\} o \{usted\} en situaciones de trato informal, y a nivel léxico por algunos préstamos procedentes de lenguas chibchas como el Muisca. Carecemos de datos para establecer las diferencias entre estos conjuntos y el Neogranadino Amazónico.

Ya a nivel subdialectal se establecen diferencias basadas en el léxico, que quedan sistematizadas en los trabajos de dialectometría y léxico sobre el ALEC reseñados, y de los cuales extraemos los límites de esas unidades diatópicas para esta propuesta.

Como observación final, la geografía juega un papel fundamental en la variación diatópica del español de Colombia, siendo la oposición Tierras bajas - Tierras altas, el grado de accesibilidad por el sur a través de la cordillera de los Andes, y la posibilidad de atravesar las tres cordilleras (especialmente la central), los tres condicionamientos más importantes que el medio le impone a la variación lingüística. Igualmente, el caso específico de las hablas del Pacífico y tal vez el de las del Llano demuestra que los condicionamientos históricos pesan sobre la articulación dialectal de Colombia, y en ese sentido se hace necesaria una aproximación diacrónica a la génesis y fijación de las variedades geográficas que pueda llegar a explicar, mediante variables como la composición y densidad poblacional, las migraciones, el fenómeno del desplazamiento forzado, o los procesos históricos de ocupación y apropiación del espacio, el estado de cosas que muestran las propuestas de división dialectal. 
Tabla 4. Nueva propuesta de división dialectal del español de Colombia ${ }^{16}$

\begin{tabular}{|c|c|c|c|}
\hline Superdialectos & Dialectos & Subdialectos & Hablas regionales \\
\hline \multirow{4}{*}{ Español Antillano } & \multirow{4}{*}{$\begin{array}{l}\text { Caribeño } \\
\text { colombiano }\end{array}$} & Cartagenero & Nte. de Bolívar / Sucre \\
\hline & & Samario & Atlántico / Magdalena \\
\hline & & Fonsequero & $\begin{array}{l}\text { Guajira / Cesar / Nte. Norte de } \\
\text { Santander }\end{array}$ \\
\hline & & Sabanero & $\begin{array}{l}\text { Córdoba / Urabá antioqueño / } \\
\text { Sur de Bolívar }\end{array}$ \\
\hline \multirow{12}{*}{$\begin{array}{l}\text { Español } \\
\text { Neogranadino }\end{array}$} & \multirow{4}{*}{ Occidental } & $\begin{array}{l}\text { Antioqueño- } \\
\text { caldense }\end{array}$ & $\begin{array}{l}\text { Antioquia / Caldas / Quindío / } \\
\text { Risaralda / Nte. del Valle del } \\
\text { Cauca }\end{array}$ \\
\hline & & Caucano-valluno & $\begin{array}{l}\text { Andes del Cauca / Valle } \\
\text { geográfico del Cauca }\end{array}$ \\
\hline & & $\begin{array}{l}\text { Pacífico } \\
\text { Septentrional }\end{array}$ & Chocó \\
\hline & & Pacífico & $\begin{array}{l}\text { Costas de Valle del Cauca, } \\
\text { Cauca y Nariño }\end{array}$ \\
\hline & \multirow{6}{*}{ Oriental } & Santandereano & $\begin{array}{l}\text { Santander / Sur de Norte de } \\
\text { Santander }\end{array}$ \\
\hline & & Cundiboyacense & Boyacá / Cundinamarca \\
\hline & & $\begin{array}{l}\text { Tolimense- } \\
\text { huilense }\end{array}$ & $\begin{array}{l}\text { Tolima / Huila / Occ. del } \\
\text { Caquetá }\end{array}$ \\
\hline & & Llanero Norte & Arauca / Casanare \\
\hline & & Llanero Sur & Meta \\
\hline & & ${ }^{*}$ Llanero Este & *Vichada \\
\hline & \multirow[t]{2}{*}{ *Amazónico } & $\begin{array}{l}\text { *Amazónico } \\
\text { Norte }\end{array}$ & *Guaviare / Guainía / Vaupés \\
\hline & & *Amazónico Sur & ${ }^{*}$ Ori. de Caquetá / Amazonas \\
\hline \multirow{2}{*}{ Español Andino } & \multirow{2}{*}{ Andino colombiano } & De tierras altas & Andes de Nariño \\
\hline & & De tierras bajas & Putumayo \\
\hline
\end{tabular}

${ }^{16}$ Nte. $=$ Norte. Ori. $=$ Oriente. Occ. $=$ Occidente

* = Marca divisiones dialectales hipotéticas dada la carencia de estudios. 
Fuente: elaboración propia con base en los datos de Ávila et al. (2015), Bonilla (2019), IGAC (2002), Mora et al. (2004) y Rodríguez-Díaz et al. (2018)

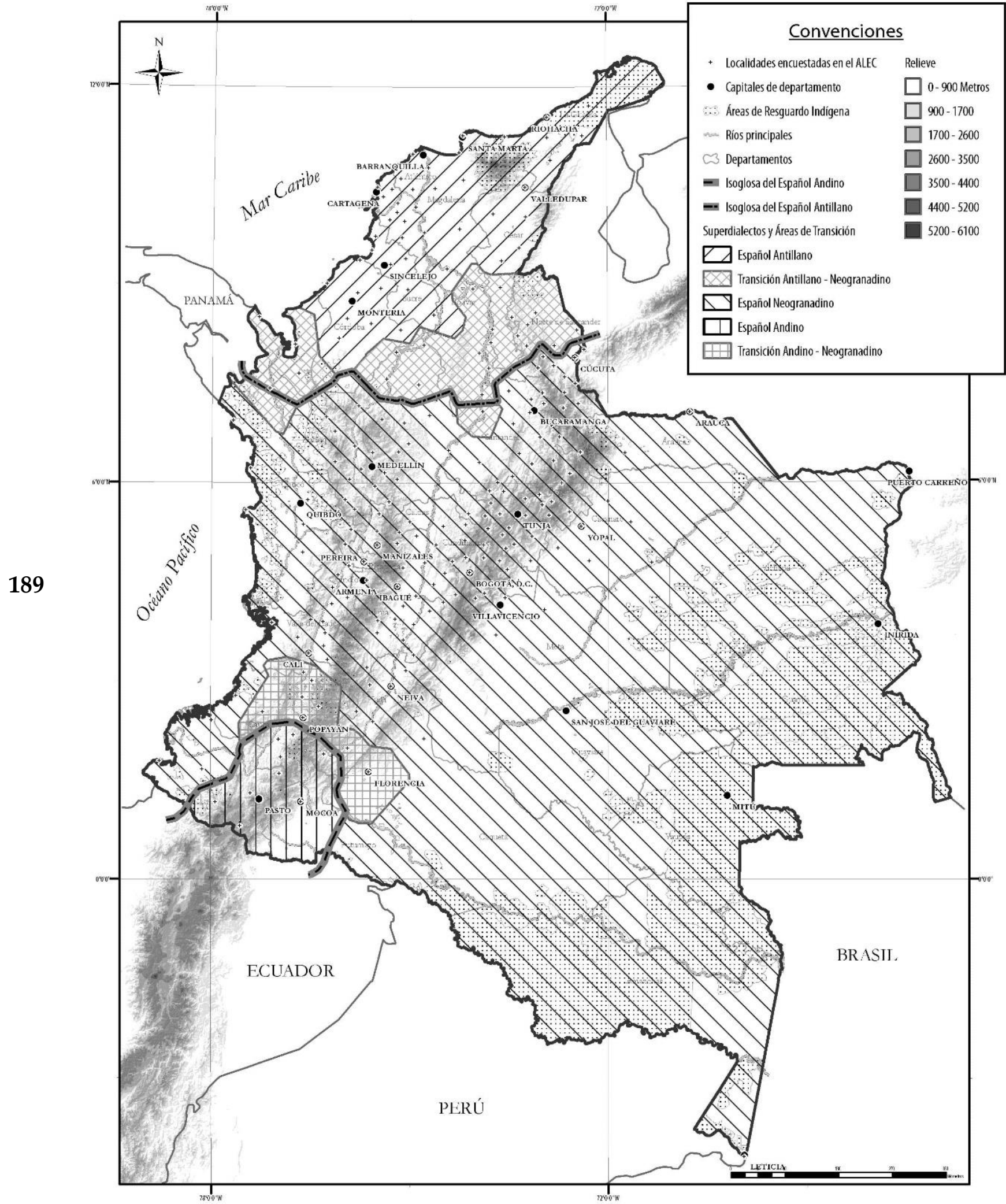

Figura 6. Superdialectos del español en Colombia 
Fuente: elaboración propia con base en los datos de Ávila et al. (2015), Bonilla (2019),

IGAC (2002), Mora et al. (2004) y Rodríguez-Díaz et al. (2018)

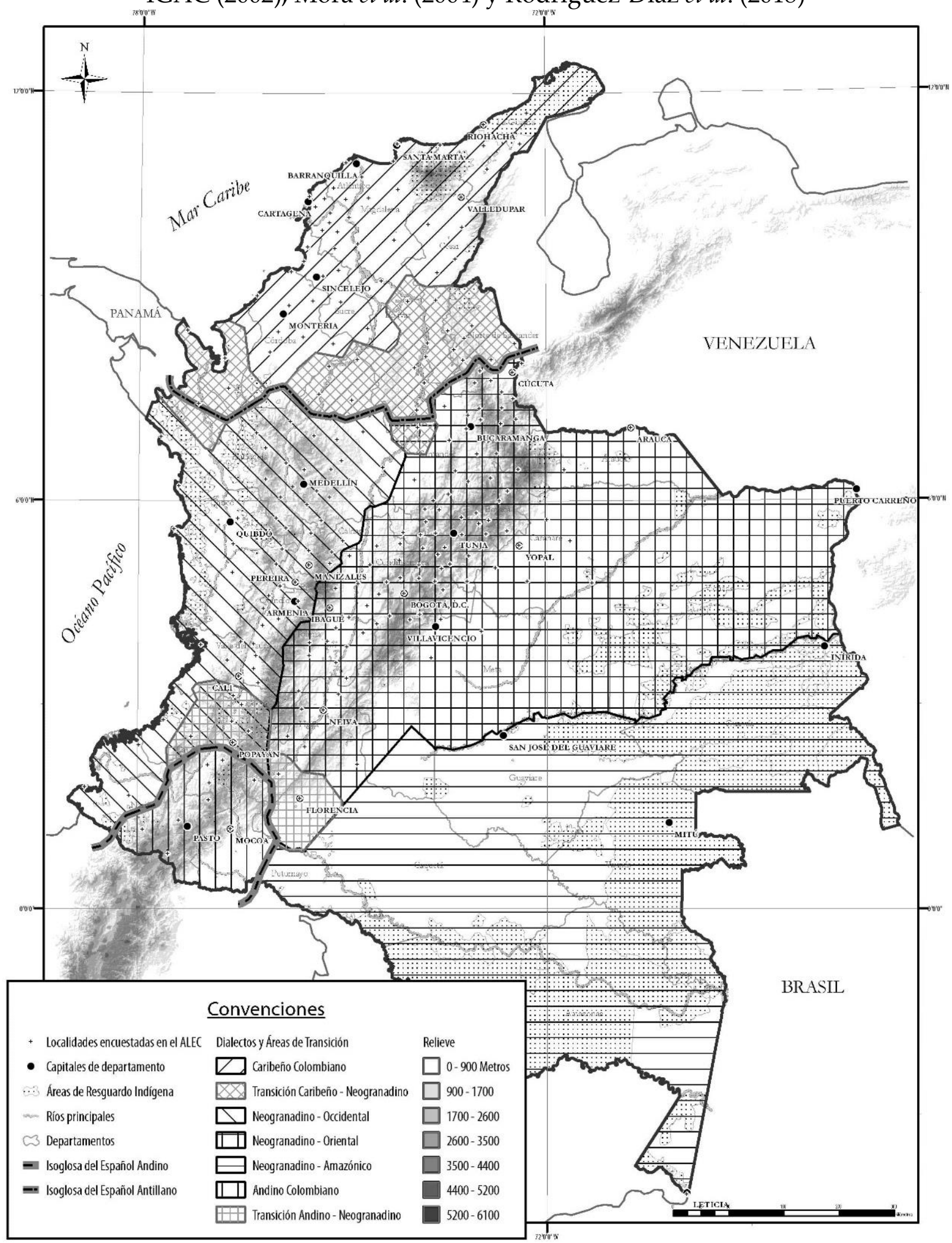

Figura 7. Dialectos del español de Colombia 
Fuente: elaboración propia con base en los datos de Ávila et al. (2015), Bonilla (2019), IGAC (2002), Mora et al. (2004) y Rodríguez-Díaz et al. (2018)

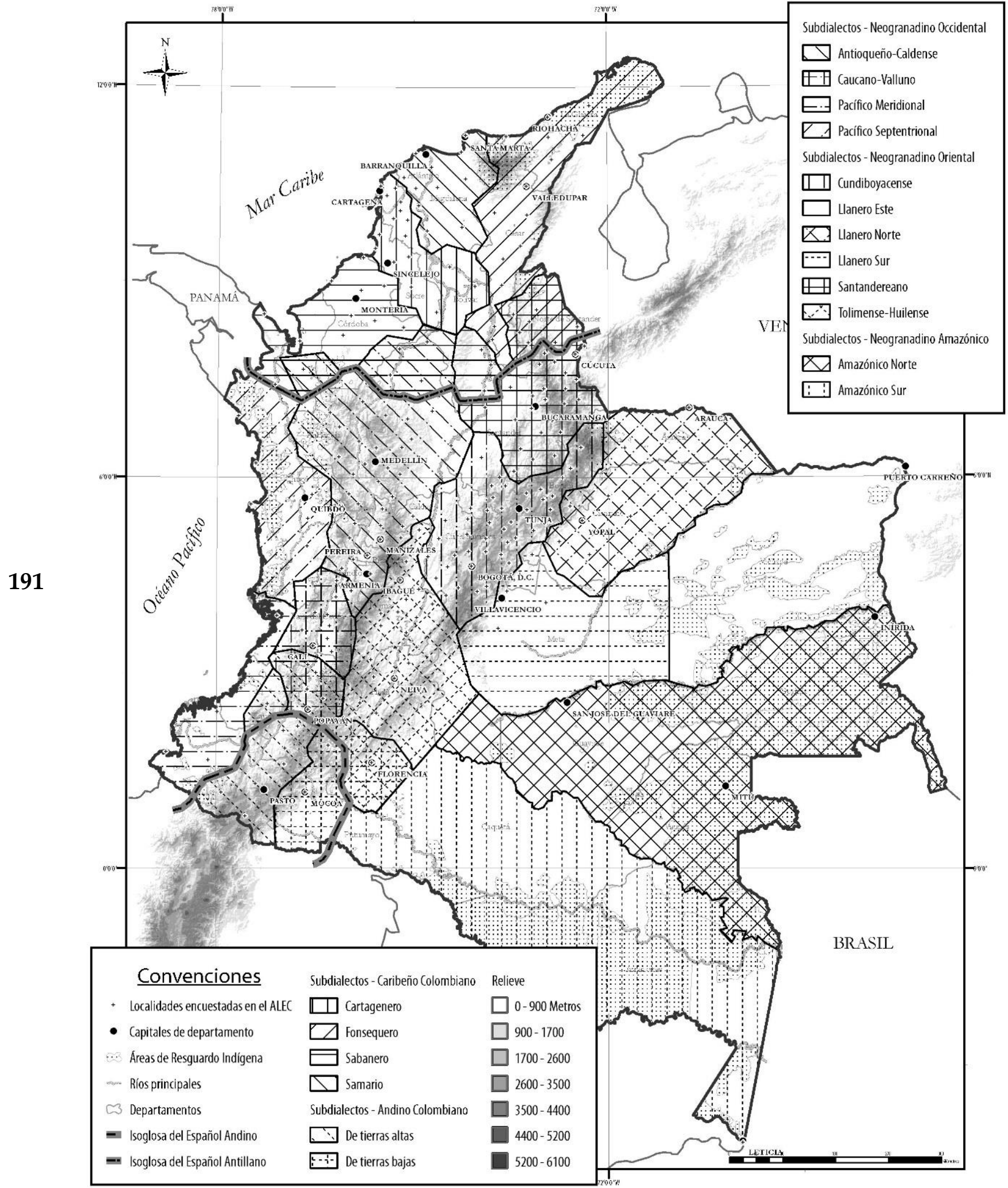

Figura 8. Subdialectos del español de Colombia 


\section{REFERENCIAS}

Alba, O. (2016). Una mirada panorámica al español antillano. Santo Domingo: Editora Nacional.

Aleza, M., y Enguita, J. M. (Coords.). (2010). La lengua española en América: normas y usos actuales. Valencia: Universitat de València.

Alvar, M. (1996). ¿Qué es un dialecto? En M. Alvar (Dir.), Manual de dialectología hispánica: el español de España (pp. 5-14). Barcelona: Ariel.

Arboleda, R. (2000). El español andino. Forma y Función, (13), 85-100. Recuperado de https://revistas.unal.edu.co/index.php/formayfuncion/article/view/17184.

Arboleda, R. (2002). El español andino (segunda parte). Forma y Función, (15), 15-40. Recuperado

de https://revistas.unal.edu.co/index.php/formayfuncion/article/view/17222.

Arboleda, R. (2012). El español andino de Nariño y Putumayo (variedad de contacto con la lengua quechua). En C. Patiño y J. Bernal (Coords.), El lenguaje en Colombia (Tomo I: Realidad lingüística de Colombia) (pp. 109-140). Bogotá: Instituto Caro y Cuervo.

Ávila, Y., Mendieta, F., Rodríguez, A., Rodríguez, C. A., y Silva, F. (2015). Análisis dialectométrico de las variedades del español de Colombia: Nuevas aproximaciones al ALEC. En J. Santos (Ed.), Armonía y contrastes: Estudios sobre variación dialectal, histórica y sociolingüística del español (pp. 107-125). Lugo: Axac.

Bernal, J., y Díaz, C. (2017). Caracterización panorámica del español hablado en Colombia: fonología y gramática. Cuadernos de Lingüística Hispánica, (29), 19-37. doi: 10.19053/0121053X.n29.2017.5845.

Bonilla, J. (2019). Propuesta de división dialectal del español de Colombia con base en el análisis dialectométrico de datos léxicos del ALEC (Tesis de Maestría). Instituto Caro y Cuervo, Bogotá, Colombia.

Brown, E. K., y Brown, E. L. (2012). Syllable-final and Syllable-initial /s/ reduction in Cali, Colombia: One variable or two? En R. File-Muriel y R. Orozco (Eds.), Colombian Varieties of Spanish (pp. 89-105). Madrid-Frankfurt: Iberoamericana/Vervuert.

Catalán, D. (1958). Génesis del español atlántico. Ondas varias a través del océano. Revista de Historia Canaria, (123-124), 233-242.

Chambers, J. K., y Trudgill, P. (1998). Dialectology (2 ${ }^{\underline{a}}$ ed.). Nueva York: Cambridge University Press.

Coseriu, E. (1981). La lengua funcional. En Lecciones de lingüística general (pp. 287-315). Madrid: Gredos.

De Granda, G. (1977). La articulación dialectal de las tierras bajas occidentales de Colombia y sus factores determinantes. Un esquema previo. En Estudios sobre un área dialectal hispanoamericana de población negra: las tierras bajas occidentales de Colombia (pp. 19-67). Bogotá: Instituto Caro y Cuervo. 
Díaz Collazos, A. (2015). Desarrollo sociolingüístico del voseo en la región andina de Colombia (1555-1976). Berlín: De Gruyter.

Díaz Romero, C. (2017). Sobre las realizaciones alofónicas aspiradas y debucalizadas de los fonemas fricativos del español hablado en Boyacá, Colombia: Observaciones fonéticas y fonológico-tipológicas exploratorias. En V. Marrero y E. Estebas (Coords.), Tendencias actuales en fonética experimental (pp. 159-162). Madrid: UNEDCSIC.

Espejo, M. (2013). Estado del yeísmo en Colombia. En R. Gómez y I. Molina, Variación yeísta en el mundo hispánico (pp. 227-236). Madrid-Frankfurt: Iberoamericana/Vervuert.

Fernández-Sevilla, J. (1980). Los fonemas implosivos en español. Thesaurus, Boletín del Instituto Caro y Cuervo, XXV(3), 456-505.

Flórez, L. (1961). El Atlas Lingüístico-Etnográfico de Colombia ALEC. Nota informativa. Thesaurus, Boletín del Instituto Caro y Cuervo, XVI(1), 77-125. Recuperado de https://cvc.cervantes.es/lengua/thesaurus/pdf/16/TH_16_001_077_0.pdf.

García, P. (1999). Dialectometría. En J. Blecua, G. Clavería, C. Sánchez, y J. Torruella (Eds.), Filología e informática: nuevas tecnologías en los estudios filológicos (pp. 335-357). Barcelona: Universitat Autònoma de Barcelona.

Goebl, H. (1987). Points chauds de l'analyse dialectométrique: pondération et visualisation. Revue de linguistique romane, (51), 63-118. Recuperado de https://www.sbg.ac.at/rom/people/prof/goebl/docs/Goebl1987_Points\%20chauds.p df.

Hualde, J., Olarrea, A., Escobar, A., y Travis, C. (2001). Introducción a la lingüística hispánica. Cambridge: Cambridge University Press.

Instituto Caro y Cuervo. (1981). Atlas Lingüístico-Etnográfico de Colombia, ALEC (Vols. 1-6). Bogotá: Instituto Caro y Cuervo.

Instituto Geográfico Agustín Codazzi (IGAC). (2002). Atlas de Colombia (5 $5^{\underline{a}}$ ed.). Bogotá: IGAC, Imprenta Nacional de Colombia.

Lancheros, H. (2018). Los indigenismos léxicos en las variedades diatópicas del español colombiano. Forma y Función, 31(2), 9-29. doi: 10.15446/fyf.v31n2.74652.

Lapesa, R. (1980). América y la unidad de la lengua española. Documentos Lingüísticos y Literarios, (5), 74-89. Recuperado de https://www.humanidades.uach.cl/documentos_linguisticos/document.php?id=72 9.

Lipski, J. (2005). El español de América. Madrid: Cátedra.

Montes, J. (1967). Sobre el voseo en Colombia. Thesaurus, Boletín del Instituto Caro y Cuervo, XXVII(1), 21-44. Recuperado de https://cvc.cervantes.es/lengua/thesaurus/pdf/22/TH_22_001_021_0.pdf. 
Montes, J. (1982). El español de Colombia. Propuesta de clasificación dialectal. Thesaurus, Boletín del Instituto Caro y Cuervo, XXXVII(1), 23-92. Recuperado de https://cvc.cervantes.es/lengua/thesaurus/pdf/37/TH_37_001_023_0.pdf.

Montes, J. (1984). Para una teoría dialectal del español. En Instituto Caro y Cuervo (Ed.), Homenaje a Luis Flórez: Estudios de historia cultural, dialectología, geografía lingüística, sociolingüística, fonética, gramática y lexicografía (pp. 72-89). Bogotá: Instituto Caro y Cuervo.

Montes, J. (1995a). Dialectología general e hispanoamericana: orientación teórica, metodológica y bibliográfica ( $3^{\underline{a}} e d$.). Bogotá: Instituto Caro y Cuervo.

Montes, J. (1995b). La bipartición dialectal del español. Boletín de Filología de la Universidad de Chile, 35(1), 317-331. Recuperado de https://boletinfilologia.uchile.cl/index.php/BDF/article/view/19233.

Montes, J. (1996). Colombia. En M. Alvar (Dir.), Manual de dialectología hispánica: El Español de América (pp. 134-145). Barcelona: Ariel.

Montes, J. (2000). Identidad de las regiones colombianas en la lengua. En Otros estudios sobre el español de Colombia (pp. 137-152). Bogotá: Instituto Caro y Cuervo.

Montes, J. (2012). El español de Colombia y el español de América. En C. Patiño y J. Bernal (Coords.), El lenguaje en Colombia (Tomo I: Realidad lingüística de Colombia) (pp. 3-10). Bogotá: Instituto Caro y Cuervo.

Mora, S. (1996). Dialectos del español de Colombia. Caracterización léxica de los subdialectos Andino-Sureño y Caucano-Valluno. Thesaurus, Boletín del Instituto Caro y Cuervo, LI(1), 1-26. Recuperado de https://cvc.cervantes.es/lengua/thesaurus/pdf/51/TH_51_001_009_0.pdf.

Mora, S., Lozano, M., Ramírez, R., Espejo, M.., y Duarte, G. (2004). Caracterización léxica de los dialectos del español de Colombia según el «ALEC». Bogotá: Instituto Caro y Cuervo.

Nieves, R. (2002). Sobre la asimilación de consonantes en algunas áreas de la Costa atlántica colombiana (Córdoba, Sucre, Bolívar). En A. Schwegler y Y. Moñino (Coords.), Palenque, Cartagena y Afro-Caribe: historia y lengua (pp. 257-266). Tubingen: Max Niemeyer Verlag.

Ordúz, Y. (2013). La pérdida de la distinción fonológica /j/- / / / en el habla bogotana. Revista Folios. Segunda época, (37), 51-62.

Palacios, M., y Safford, F. (2002). Historia de Colombia. País fragmentado, sociedad dividida. Bogotá: Universidad de los Andes.

Quesada, M. (2014). División dialectal del español de América según sus hablantes Análisis dialectológico perceptual. Boletín de Filología, 49(2), 257-309. Recuperado de https://boletinfilologia.uchile.cl/index.php/BDF/article/view/35862.

Ramírez, A., y Almira A. (2016). Variación del fonema /s/ en contextos de juntura de palabra en el español caleño: una mirada sociolingüística. Lenguaje, 44(1), 11-33. doi: 10.25100/lenguaje.v44i1.4628. 
Ramírez, M. (2015). De la [s], [sh], [h], [?], Ø, a la [z], [z]: Continuo de variación de /s/ en posición de coda silábica en el español de Colombia. En J. Santos (Ed.), Armonía y contrastes: Estudios sobre variación dialectal, histórica y sociolingüística del español (pp. 127-139). Lugo: Axac.

Rodríguez Cadena, Y. (2006). El español del caribe colombiano. En A. Cestero, I. Molina, y F. Paredes (Coords.), Estudios sociolingüísticos del español de España y América (pp. 179-185). Madrid: Arco Libros.

Rodríguez-Díaz, C. A., Jiménez, S., Dueñas, G., Bonilla, J., y Gelbukh, A. (2018). Dialectones: Finding Statistically Significant Dialectal Boundaries Using Twitter Data. Computación y Sistemas, 22(4), 1213-1222. Recuperado de https://www.cys.cic.ipn.mx/ojs/index.php/CyS/article/view/3104/0.

Rona, J. (1964). El problema de la división del español americano en zonas dialectales. En Presente y futuro de la lengua española (pp. 215-226). Madrid: Ediciones Cultura Hispánica.

Ruiz, N. (2014). El léxico de la muerte en el español hablado en Colombia, según el ALEC. Bogotá: Instituto Caro y Cuervo.

Sánchez, L. (Ed.). (2012). Geografía humana. Conceptos básicos y aplicaciones. Bogotá: Ediciones Uniandes.

Sobrino, R. (2018). Las variedades de español según los hispanohablantes: corrección, incorrección y agrado lingüísticos. Cuadernos de lingüística de El Colegio de México, 5(2), 79-119. Recuperado de https://cuadernoslinguistica.colmex.mx/index.php/cl/article/view/115.

Zamora, J., y Guitart, J. M. (1982). Dialectología hispanoamericana. Teoría, descripción, historia. Salamanca: Almar.

\section{SOBRE EL AUTOR}

\section{Néstor Fabián Ruiz Vásquez}

Doctorando en Lingüística por la Universidad del País Vasco. Magister en Lingüística Española por el Instituto Caro y Cuervo. Investigador de planta en lingüística diacrónica del español y cambio y variación lingüística del Instituto Caro y Cuervo; docente titular de la Maestría en Lingüística de la Facultad Seminario Andrés Bello. Director del Grupo de Estudios Históricos de Lenguas de Colombia (GEHLC), y del proyecto de investigación Documentos para la historia lingüística de Colombia, siglos XVI a XIX (Instituto Caro y Cuervo, 2014 - a la fecha).

Correo electrónico: nestor.ruiz@caroycuervo.gov.co

Orcid: 0000-0003-0792-4129. 